\title{
On rapid multidisciplinary response aspects for Samos 2020 M7.0 earthquake
}

\author{
Michael Foumelis ${ }^{1} \cdot$ Costas Papazachos $^{2} \cdot$ Eleftheria Papadimitriou $^{2} \cdot$ Vasileios Karakostas $^{2} \cdot$ Dimitrios Ampatzidis $^{1}$. \\ Giorgos Moschopoulos ${ }^{3} \cdot$ Anastasios Kostoglou $^{2} \cdot$ Maya llieva $^{4} \cdot$ Despina Minos-Minopoulos $^{5}$. \\ Antonios Mouratidis ${ }^{1} \cdot$ Charalambos Kkallas $^{2} \cdot$ Alexandros Chatzipetros $^{6}$
}

Received: 31 December 2020 / Accepted: 19 March 2021 / Published online: 28 March 2021

(c) Institute of Geophysics, Polish Academy of Sciences \& Polish Academy of Sciences 2021

\begin{abstract}
Following the M7.0 earthquake that struck the Greek island of Samos and Turkey's western coast, causing extensive damage and casualties, we combined existing knowledge geodatabases concerning historical seismicity and rupture zones with seismological and geodetic measurements as well as with modelling and in situ observations, to provide an assessment of rapid response to the seismic event. In this paper, we demonstrate that in the frame of the gradual provision of information from the individual scientific disciplines, taking into account their respective potential and limitations, a multidisciplinary approach is able to address more efficiently rapid response issues in order to allow effective preliminary interpretation of the earthquake activity, even within the first $24 \mathrm{~h}$ of the event. It focuses on the assessment of the timely provision of information by each discipline, evaluating the access to primary data sources as well as the maturity of the techniques in terms of accuracy and rapid data processing. Within a period of less than a week, several constraints were partially compensated for, allowing the delivery of more robust results and interpretation. The study highlights the readiness level of the various domains that has been significantly improved over the past years, including rapid seismological solutions, systematic availability of free and open Earth Observation data and on-demand online processing through dedicated platforms. Their combination with routinely applied inversion modelling and timely in situ observation is leading to improved operational response levels.
\end{abstract}

Keywords Rapid response $\cdot$ Seismology $\cdot$ Imaging geodesy $\cdot$ GNSS $\cdot$ Fault modelling $\cdot$ Earthquake environmental effects

\section{Introduction}

On 30 October 2020, a powerful earthquake struck Turkey's western coast and the Greek island of Samos, causing extensive damage as well as casualties. Based on the Hellenic Unified Seismological Network (H.U.S.N.) the moment magnitude (M) 7.0 mainshock-which was felt as far away as Athens and Istanbul—had its focal depth between 10 and $15 \mathrm{~km}$. It was the strongest earthquake to have hit Samos since 1955, when the island was struck by a M6.9 earthquake along its southern coasts, and similar 1904 M6.8

Communicated by the Guest Editors: Ramon Zuniga, Eleftheria Papadimitriou, Vassilios Karakostas and Onur Tan.

Michael Foumelis

mfoumelis@geo.auth.gr

Extended author information available on the last page of the article earthquake, which most probably occurred on a sub-parallel onshore fault.

Following the event, a tsunami hit the northern coasts of Samos, with estimated maximum run up height of 1.5-2 m and inundation reaching $\sim 100 \mathrm{~m}$. It flooded the northern harbors of Samos, amplifying the structures damage. Localized and restricted slope failures in terms of rock falls were recorded mainly along road-cut slopes in the north of the island, (e.g., Avlakia). Ground fractures were recorded in the northeastern part of the island, mainly in the regions of Agios Nikolaos and Kontakeika villages, near Karlovasi (Lekkas et al. 2020).

As early information on the earthquake is usually based on seismic data, the initial location of the epicenter and the rough distribution of first aftershocks were provided almost in real time. Concerning the rapid response, just a few hours after the event, thanks to the availability of synthetic aperture radar (SAR) data acquired from the Sentinel-1 mission of the European Union's Copernicus Programme, on the same day 
as the earthquake and less than $12 \mathrm{~h}$ apart, several scientific groups communicated their Differential Interferometric SAR (DInSAR) results on social media (Twitter, LinkedIn, Facebook, etc.) or by preliminary reports (Chatzipetros et al. 2020; Ganas et al. 2020; Lekkas et al. 2020; Papadimitriou et al. 2020; Segou 2020). This information was available in addition to solutions obtained from regional GNSS networks covering the affected area (Ganas et al. 2020).

Following the event, the Aristotle University of Thessaloniki (AUTh) initiated DInSAR processing using several on-demand services hosted on the Geohazards Exploitation Platform (GEP, https://geohazards-tep.eu) (Foumelis et al. 2019). It was applied to map the spatial distribution of coseismic ground displacements (ESA Sentinel Online 2020). Processing results were immediately made accessible to the scientific community as well as authorities and the wider public through the GEP community area (GEP 2020).

In the current work, we combined existing knowledge geodatabases, concerning historical seismicity and rupture zones, together with seismological and geodetic observation as well as modelling to rapidly respond to the M7.0 Samos event. Our intent is not to replicate existing technical reports on the preliminary findings concerning the earthquake, but to outline the capacity to rapidly respond to such events detailing the contribution of several scientific disciplines as well as aspects related to data accessibility and processing infrastructures. We also focus on the existing limitations of the individual techniques in terms of rapid estimates directly after the event. Moreover, we also discuss how the same approaches are gradually improving, both in terms of accuracy of the solutions, as well as regarding the extraction of additional parameters within a multidisciplinary framework. The possibility to optimize our knowledge of such geohazard phenomena, using the synergy of the individual techniques is also examined.

Our goal is to evaluate what current technologies can provide, improving our past capabilities, especially in the case of future events for regions not adequately monitored by in situ networks. We also show how such limitations have been partly overcome by the widespread use of Earth Observation (EO) and geodetic data, including initiatives offering both open access to data, as well as processing services. The contribution of existing data in terms of historical seismicity and tectonic structures is also analyzed and the question of whether such information, even contradicting scenarios, can contribute to the improvement of rapid response to earthquakes is discussed.

In the following, we present various independent rapid response results and their constraints by several thematic domains, contributing to improved earthquake risk assessment. Moreover, we discuss how multidisciplinary data may adequately fill gaps in our current understanding for such phenomena, allowing better preliminary interpretations during the rapid response phase.

\section{Geotectonic setting and historical seismicity}

Samos island is essentially an elongated complex horst structure, bounded by roughly WSW-ENE to WNW-ESE trending normal fault zones. This geometry is in good agreement with the overall deformation pattern of the Western Anatolia Graben System (WAGS). The general N-S trending extension is active since Late Miocene-Early Pliocene, as indicated by stratigraphical and geological evidence in both the western Turkey, as well as in Samos (e.g., Weidmann et al. 1984; Yilmaz et al. 2000; Mountrakis et al. 2003, 2006). Older low-angle normal faults, associated with the exhumation of the metamorphic bedrock, have also been reactivated during this latest extensional phase and show indications of strike-slip deformation. The ongoing deformation led to an asymmetric development of normal faulting, with the offshore fault zone dipping with moderate angles to the North, while the southern onshore fault zone is generally steeper and dipping to the South.

A critical factor for the rapid assessment of major earthquakes (like the M7.0 2020 Samos earthquake) is the ability to have a good understanding of the seismotectonic setting of the broader area where the mainshock has occurred. Typically, this assessment is performed on the basis of previous studies and existing data, such as databases and research work on active faults, historical and instrumentally recorded seismicity (including previous similar mainshocks and their aftershock sequences), stress field and active crustal deformation (e.g., GNSS data). Similar results not only contribute to the understanding of the geotectonic context within which the mainshock has occurred, but also to obtain valuable information on the possible evolution of the seismic sequence (e.g., triggering of secondary faults), as well as its impact in the broader area (e.g., historical seismicity, damage patterns, occurrence of secondary phenomena such as tsunami, landslides, liquefaction, etc.).

Figure 1a presents the major active faults of the broader Samos area, as presented in several active fault databases (e.g., GreDaSS; Caputo et al. 2012; Sboras 2012; NOAv3.0; Ganas et al. 2020), as well as from other researchers (Mountrakis et al. 2003; Chatzipetros et al. 2013; Sakellariou and Tsampouraki-Kraounaki 2019). In the same plot, fault plane solutions (FPS) from moderate to strong events ( $\mathbf{M} \geq 4.5)$ for the same area are presented, classified according to their type. We also plot the sub-horizontal $\left(\operatorname{dip} \leq 45^{\circ}\right)$ kinematic axes (P and T) for each FPS, as well as the FPS of the Samos M7.0 mainshock. From this plot, several interesting conclusions can be drawn: 
Fig. 1 a Fault Plane Solutions (FPS) for events with $\mathbf{M}>4.5$ (dark red: Normal faulting, Blue: Strike-slip) and associated $\mathrm{P}$ and $\mathrm{T}$ kinematic axes in the broader Samos area (only axes with dip $\leq 45^{\circ}$ are plotted). The 2020 M7.0 FPS is depicted with light red color. Major active faults compiled from various sources are also depicted (KAF: Kaystrios fault [which hosted the 2020 sequence], FF: Fourni, PF: Pythagoreion, KDF: Karlovasi-Drakeon, KVF: KokkariVathy, CTF: Cape Tsopelas, YF: Yavansu, PSF: PrieneSazli, CCF: Chios-Cesme, KF: Karaburun, SF: Sigacik, TF: Tuzla, SMF: Smyrni). b Historical and instrumental seismicity in the same region (Yellow circles: historical and early instrumental events, White circles: Recent (post-1965) seismicity, Red circles: Major historical and twentieth-century earthquakes in Samos since mid-eighteenth century, see text for explanation)

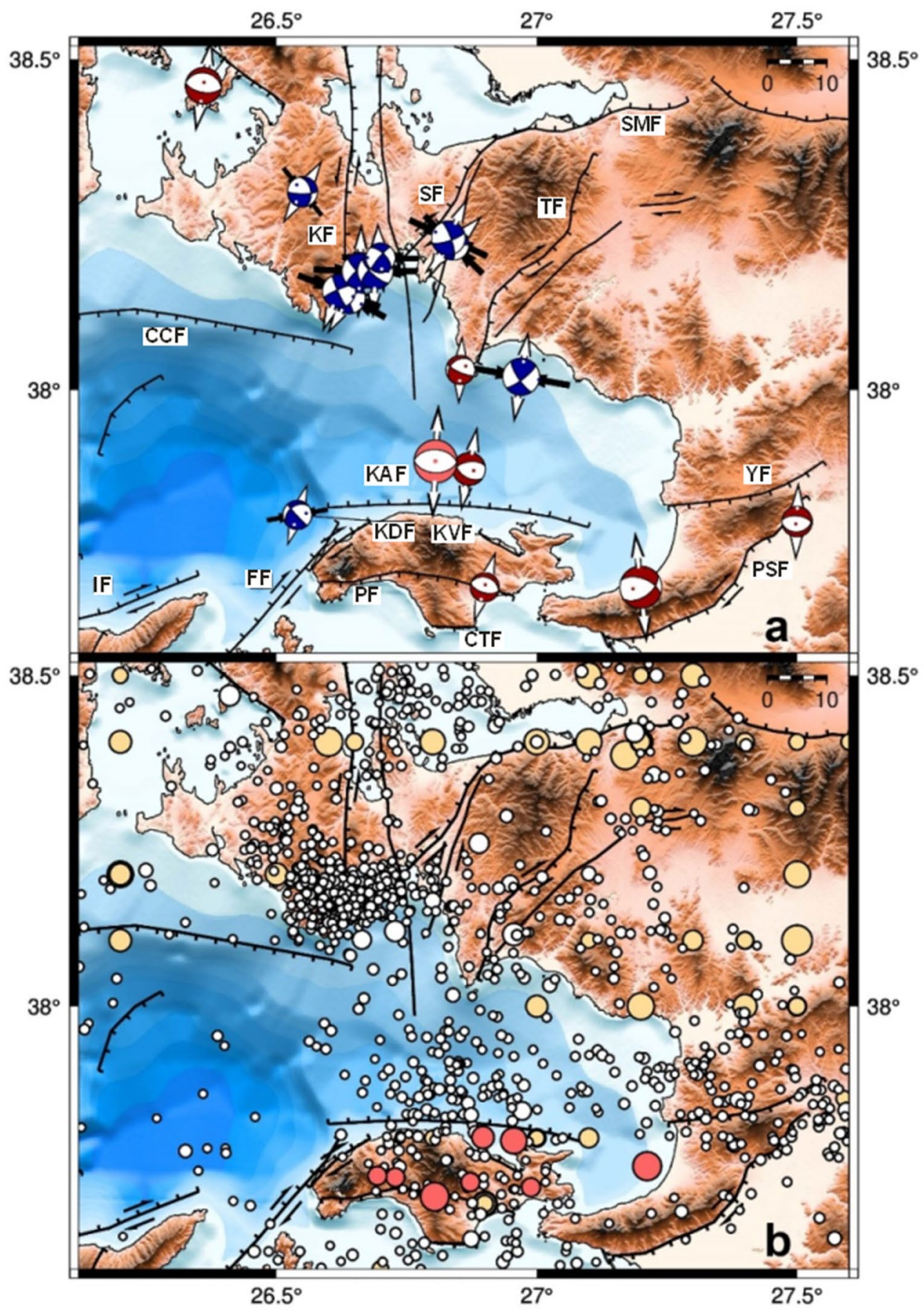

a) The earthquakes occurred on a previously identified fault, named Kaystrios fault in the GreDaSS database (Caputo et al. 2012; Sboras 2012), also identified as North Samos fault in Chatzipetros et al. (2013). While this fault has been identified mainly based on morphotectonic evidence, it is important to notice that it is one of the relatively rare cases for the Aegean area where a major mainshock occurred along a previously identified offshore fault. For most previous offshore mainshocks in the Aegean, the seismogenic faults were either not previously identified (e.g., the 2001 Skyros M6.4 earthquake, Karakostas et al. 2003) or were associated with a deeper crustal fault (e.g., subduction event), not having a clear surface fault trace (e.g., the 2018 Zakynthos M6.7 mainshock, Karakostas et al. 2020; Papadimitriou et al. 2021).

b) The broader Samos area is characterized by the presence of roughly E-W trending normal faults, similar to the 
M7.0 2020 seismogenic fault. These faults locally obtain a more ENE-WSW orientation, exhibiting a combination of normal and dextral strike-slip motions, as also confirmed by the available FPS data. To the north, the Sigacik area and the Cesme peninsula are dominated by the presence of NE-SW trending strike-slip faults, such as the Tuzla Fault and Sigacik Faults (TF and SF in Fig. 1a), which are very similar to the faults found in western Samos. The associated T axes have an approximately NNE-SSW direction, occasionally coupled with a WNW-ESE compression, as observed in strike-slip faults. This stress regime controls the faulting pattern, resulting in mainly normal motions along E-W striking faults, changing to dextral strike-slip for NE-SW trending faults, and even to sinistral strike-slip for NNWSSE trending faults, such as the Karaburun Fault (KF in Fig. 1a).

This complicated transtensional regime and the associated crustal deformation in the area (Papazachos and Kiratzi 1996; Nocquet 2012; Papazachos 2019) has resulted in the generation of several significant mainshocks, as observed in both the historical and instrumental seismicity record. In Fig. 1b, we present the broader Samos area, historical and pre-1965 (early instrumental) seismicity ( $\mathbf{M} \geq 5.0$, yellow circles) from the catalog of Papazachos et al. (2000), as well as the recent instrumentally recorded seismicity between 1965 and 2010 ( $\mathbf{M} \geq 3.5$, white circles), as relocated by Tan et al. (2014) and homogenized as far as earthquake magnitudes concern by Leptokaropoulos et al. (2013). In the same plot, we also present the major historical and twentieth-century earthquakes in the vicinity of Samos since mid-eighteenth century (red circles), as presented in Papazachos and Papazachou (2003) and the sources listed by the same authors. The corresponding information for these important Samos events is also listed in Table 1. Again, several inferences can be made from Fig. $1 b$ (and Table 1):

Table 1 Information (coordinates, year, moment magnitude) on historical (post mid-eighteenth century) and instrumentally recorded (twentieth century) strong earthquakes in the vicinity of Samos (red circles in Fig. 1b). Adapted from Papazachos and Papazachou (2003)

\begin{tabular}{llll}
\hline Lon & Lat & Year & \multicolumn{1}{l}{ M } \\
\hline 27.21 & 37.76 & 1751 & $\sim 6.8$ \\
26.69 & 37.74 & 1831 & $\sim 5.5$ \\
26.73 & 37.74 & 1846 & $\sim 5.5$ \\
26.99 & 37.72 & 1865 & $\sim 5.5$ \\
26.87 & 37.73 & 1868 & $\sim 5.5$ \\
26.96 & 37.80 & 1873 & 6.5 \\
26.90 & 37.80 & 1877 & 6.0 \\
26.80 & 37.71 & 1904 & 6.8 \\
26.84 & 37.59 & 1955 & 6.9 \\
\hline
\end{tabular}

a) The broader Samos area is characterized by high seismicity levels, with several strong events $(\mathbf{M}>6.5)$ in both historical and instrumental seismicity records.

b) A significant number of strong events $(\mathbf{M}>5.5)$ is associated with the faults located in the vicinity of Samos island. Some information is available for Samos since antiquity [e.g., the 200BC strong earthquake (M6.0 6.5), with maximum macroseismic intensities around $7-8$ in the Modified Mercalli scale $\left(\mathrm{I}_{\mathrm{MM}}\right.$ hereinafter), and the 47AD M 7.0 mainshock that resulted in heavy damage $\left(\mathrm{I}_{\mathrm{MM}} \sim 8\right)$ in Samos and several Ionian cities in Asia Minor, e.g., Papazachos and Papazachou 2003]. However, the main historical sources for Samos include information after the mid-eighteenth century, starting with the strong $1751 \mathrm{M} \sim 6.8$ earthquake. Samos suffered heavy damage from this event (collapses in Chora, Vathy, etc.), similar to coastal Turkey (Kuşadasi, Agacli, broader mountain Dilek-Mykali area).

c) A large number of moderate to strong (M5.5-6.0) earthquakes occurred during the nineteenth century, mainly on the Samos Island $(1831,1846,1868)$. Moreover, stronger events (M6.0-6.5) occurred along the northeast coasts of Samos at the end of the nineteenth century (1873 and 1877). However, none of these events seem to have occurred along the Kaystrios Fault (KAF), where the M7.0 Samos seismic sequence took place.

d) The available information for the $1904 \mathrm{M} \sim 6.8$ earthquake suggests that this was a major earthquake, which partly destroyed ( $\left.\mathrm{I}_{\mathrm{MM}} \sim 8\right)$ several settlements and towns (Koumeika, Skoureika, Pirgos, Chora, Ano Vathy, Agia Triada, etc.) along the Pythagoreion fault (PF in Fig. 1a), suggesting that this earthquake was associated with this seismogenic fault. This is supported by the lack of any information on tsunami observations, verifying that this event was (most probably) not generated on an offshore fault.

To further verify this suggestion, we constructed a stochastic simulation model (Fig. 2) for the damage distribution (as mapped by the available macroseismic information), assuming that the event occurred along the south-dipping normal Pythagoreion Fault. For the modelling we used the EXSIM the finite-fault stochastic simulation algorithm (Motazedian and Atkinson 2005), as adapted by Boore (2009). In the simulation, the source, path and site-effect parameters were based on the procedure proposed by Papazachos et al. (2016) and Kkallas et al. (2018). The results presented in Figure 2 show a very good agreement regarding both the spatial distribution of macroseismic intensities, as well as the actual $\mathrm{I}_{\mathrm{MM}}$ values predicted by the modelling. This correlation suggests that we 
Fig. 2 Simulated macroseismic intensity distribution from the stochastic simulation of the 1904/08/11 M 6.8 mainshock (contours labeled with Latin numbers). In the same plot the original $\mathrm{I}_{\mathrm{MM}}$ observations (colored circles) are also plotted. A similar plot for the near fault area is presented in the top-left inset figure (observed $\mathrm{I}_{\mathrm{MM}}$ values depicted with numbers). The correlation of observed $\left(\mathrm{I}_{\mathrm{MM}}{ }^{\mathrm{Obs}}\right)$ and simulated $\left(\mathrm{I}_{\mathrm{MM}}{ }^{\text {Sim }}\right)$ values is shown in the top-right inset figure. The results support the adopted simulation scenario, which suggests that this event occurred along the Pythagoreion Fault (PF in Fig. 1, schematically depicted here with a blue line)

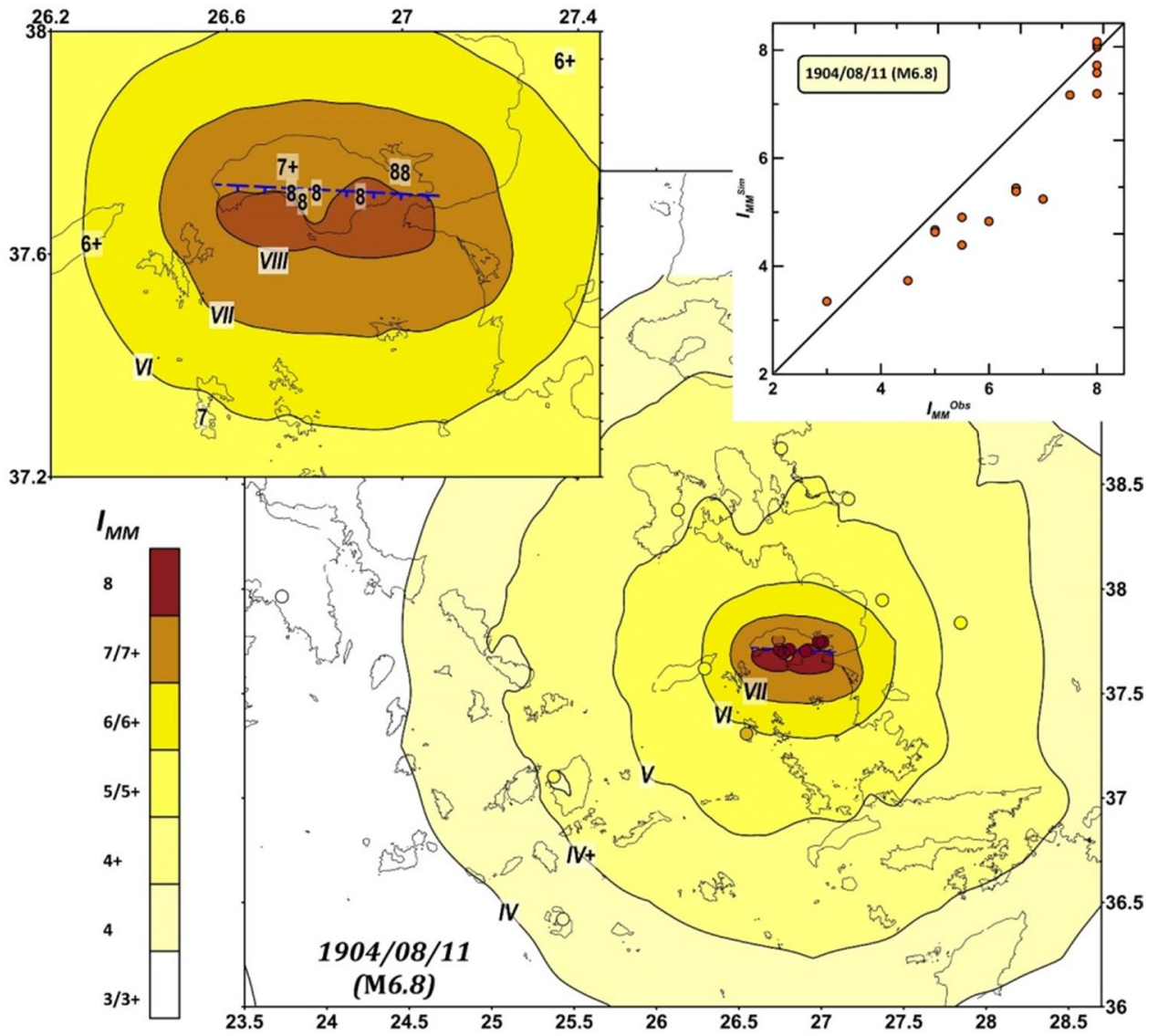

can efficiently model the damage distribution of the 1904 earthquake by assuming a rupture on the Pythagoreion Fault (PF).

e) The 1955 July 16 M6.9 earthquake most probably occurred on an offshore fault, associated with the Cape Tsopelas Fault (CPF) in southern Samos and the westward edge of the Priene-Sazli Fault (PSF) (see Fig. 1). This is verified by modelling of the macroseismic intensities (Kiratzi et al. 2020), as well as reports on tsunami observations in southern Samos.

The abovementioned information is important for the rapid assessment and response for the M7.0 Samos earthquake, since:

a) It is evident that the 2020 mainshock occurred on a previously identified normal fault, compatible with the geotectonic setting and the active stress field of the area, facilitating the quick and reliable identification of the Kaystrios causative seismogenic fault. The available historical and instrumental seismicity records suggest that this fault has not hosted a large $(\mathbf{M} \sim 7.0)$ mainshock after the mid-eighteenth century. On the contrary, two (2) similar events occurred in the normal onshore
Pythagoreion fault (1904, M6.8) and a second normal offshore southern Samos (1955, M6.9).

b) A possible exception concerns the $1873 \mathrm{M} \sim 6.5$ and $1877 \mathrm{M} \sim 6.0$ events, that may have ruptured a part of the eastern Kaystrios fault segment. This observation is compatible with the observed surface deformations (later discussed), as these are revealed from the available GNSS and DInSAR data (e.g., Figs. 5, 6, 7, 8, 9, 10, and 11), which suggest that the largest surface deformations occurred in western Samos. It should be noticed that these observations are also in agreement with preliminary results (Kiratzi et al. 2020; Okuwaki 2020; Karakostas et al. 2021) suggesting that the western fault segment that ruptured during the M7.0 2020 mainshock exhibited the largest co-seismic slip.

c) The three latest large mainshocks (1904 M6.8, 1955 M6.9, 2020 M7.0) had a relatively limited impact on Samos Island (considering their magnitude), with a small number of casualties (4 in 1904, none in 1955, 2 in 2020), though with widespread heavy damages. This similarity suggests that while these events have important consequences in the broader Samos area, the associated strong motions and impact (see also simulations of Fig. 2) are not devastating, most probably due to the 
type of faulting (normal faults typically produce lower ground motion levels, e.g., Boore et al. 2014), the fault geometry and/or the type of constructions in Samos.

\section{Rapid responses to Samos earthquake}

\section{Seismology}

The recordings of the stations belonging to the Hellenic Unified Seismological Network (HUSN) were combined with records of stations from neighboring countries, that are mainly located close to the national borders and are available online. In the current case, the seismological stations located in the nearby Turkish coasts provided critical information regarding the location quality. An unfortunate circumstance is related with the seismological station operated on the Samos Island (with the code name SMG), located very close to the activated area, which was out of operation on the mainshock occurrence date. The azimuthal coverage during the first day of the seismic sequence was adequate (less than $150^{\circ}$ ) and the density of the stations was deemed as rather satisfactory (three stations in epicentral distances less than $100 \mathrm{~km})$.

\section{Rapid aftershocks location}

In addition to the identification of the main event location, the outline of the aftershock area dimensions is a task of great importance, since this knowledge allows the reliable assessment of the seismic sequence evolution and estimation of critical parameters. This makes the rapid aftershock location, which is the basis for this identification, one of the first priorities for the scientific community after a mainshock occurrence. Figure 3 illustrates aftershock locations from the earthquake bulletin of the Geophysics Department of the AUTh (http://geophysics.geo.auth.gr/ss/; https://doi.org/10. 7914/SN/HT). Earthquake locations are automatically performed after automatic detection and then reviewed event by event during the routine analysis, where erroneous auto picks are corrected, and more phase picks are added that have been missed in the autodetection.

An initial improved location was obtained for 207 earthquakes in the first $24 \mathrm{~h}$ after the mainshock occurrence and was included in the bulletin. For the aftershock location performed by an analyst, a 1-D regional velocity is employed, considering that the routine analysis concerns the entire Greek territory, composed of two layers above half-space (Panagiotopoulos and Papazachos 1985). The velocities of $\mathrm{P}$ waves in each layer and the half-space, and the thickness of each layer are the following: $\mathrm{v}_{\mathrm{g}}=6.0 \mathrm{~km} \times \mathrm{sec}^{-1}, \mathrm{~d}_{1}=19 \mathrm{~km}$, $\mathrm{v}_{\mathrm{b}}=6.6 \mathrm{~km} \times \mathrm{sec}^{-1}, \mathrm{~d}_{2}=12 \mathrm{~km}, \mathrm{v}_{\mathrm{n}}=7.9 \mathrm{~km} \times \mathrm{sec}^{-1}$, corresponding to the upper and lower crust and the mantle. The $\mathrm{v}_{\mathrm{p}} / \mathrm{v}_{\mathrm{s}}$ ratio is considered equal to 1.78 , as it has been obtained by the Wadati method, using recordings in regional distances. For the data processing, the HYPOINVERSE computer code (Klein 2000) was used.

The spatial distribution of the first $24 \mathrm{~h}$ aftershocks shows an almost E-W extent (Fig. 3), which is in agreement with the rapid global centroid moment tensor solution (GCMT; http://www.globalcmt.org/CMTsearch.html) suggesting almost pure normal faulting with fault plane orientations strike $=270^{\circ}$, dip $=37^{\circ}$, and rake $=-95^{\circ}$. Strike-normal vertical cross sections were constructed, aiming to reveal the fault geometry. The width of the first five cross sections $\left(\mathrm{P}_{1}-\mathrm{P}_{5}\right)$ is equal to $5.7 \mathrm{~km}$ along either side of each crosssection, while for the last one (P6) it is equal to $8.5 \mathrm{~km}$. Their surface projections are shown in Fig. 3, the first five are normal to the main rupture strike, which was considered equal to $280^{\circ}$, since after several attempts it was found that

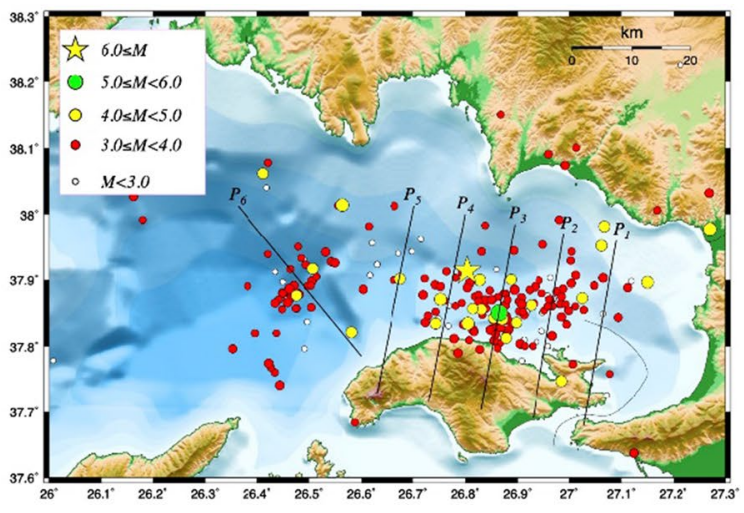

(a)

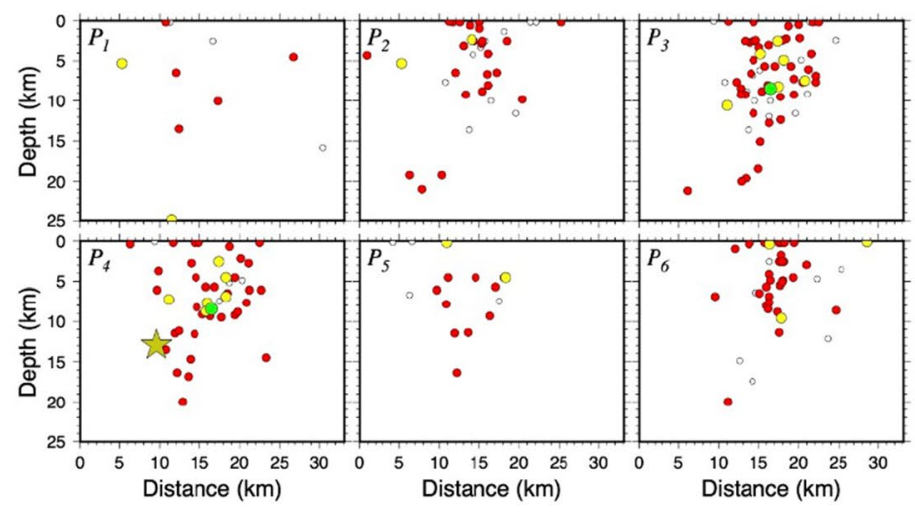

(b)
Fig. 3 a Epicentral distribution for 207 aftershocks that occurred in the first $24 \mathrm{~h}$ after the mainshock occurrence (30 October 2020 11:51 UTC), as they are listed in the bulletin of the Geophysics Department of AUTh. b Aftershock depth distribution along strike-normal vertical cross sections (surface projections are shown in Fig. 1a) 
they form the narrowest aftershock zones. The sixth one is normal to the prevalent direction of the western cluster $\left(228^{\circ}\right)$ which agrees very well with morphological features of the sea bottom in the area. A considerable percentage of the initially located seismicity appears very superficial (very close to the Earth's surface), which is not consistent with the mechanical properties of the seismogenic layer. The cross-sections $\mathrm{P}_{3}$ and $\mathrm{P}_{4}$ suggest a northward fault dip, rather steeper than the one suggested by the GCMT solution, which is not incompatible with what is shown in cross-sections $\mathrm{P}_{2}$ and $\mathrm{P}_{5}$. The $\mathrm{P}_{6}$ section suggests a rather vertical hypocentral distribution of the activated fault segment, albeit the considerable scattering.

\section{Aftershocks relocation}

To better resolve the previously presented near-real-time seismicity locations, a local velocity model and travel time corrections of the recordings of the seismological stations at epicentral distances up to $300 \mathrm{~km}$ were employed, along with a rapid check of problematic phase picks. We used additional stations from the Turkish seismological networks to confront the shortage of seismological stations at the proper distances and azimuthal coverage. The closest station to the earthquake sequence with available recordings was located at a distance of $55 \mathrm{~km}$ (BLCB, Balcova, Turkey). Data were relocated using the recordings of 27 seismological stations up to a distance of $300 \mathrm{~km}$. The lack of seismological stations in the epicentral area, as it usually occurs for offshore study areas, influences the location accuracy, especially the focal depths. To improve the accuracy, only the earthquakes clearly recorded to at least five nearest stations were relocated. A multilayered $\mathrm{P}$ wave velocity model previously derived from seismic tomography was used (Akyol et al. 2006), with the following values for velocities of $P$ waves in each layer and the half-space, and the thickness of each layer: $\mathrm{v}_{1}=4.7 \mathrm{~km} \times \mathrm{sec}^{-1}, \mathrm{~d}_{1}=1.5 \mathrm{~km}, \mathrm{v}_{2}=5.1 \mathrm{~km} \times \mathrm{sec}^{-1}$, $\mathrm{d}_{2}=3.01 .5 \mathrm{~km}, \mathrm{v}_{3}=5.8 \mathrm{~km} \times \mathrm{sec}^{-1}, \mathrm{~d}_{3}=2.0 \mathrm{~km}$, $\mathrm{v}_{4}=6.0 \mathrm{~km} \times \mathrm{sec}^{-1}, \mathrm{~d}_{4}=10.0 \mathrm{~km}, \mathrm{v}_{5}=6.3 \mathrm{~km} \times \mathrm{sec}^{-1}$, $\mathrm{d}_{5}=6.0 \mathrm{~km}, \mathrm{v}_{6}=6.4 \mathrm{~km} \times \mathrm{sec}^{-1}, \mathrm{~d}_{6}=8.0 \mathrm{~km}$, and $\mathrm{v}_{\mathrm{n}}=7.8 \mathrm{~km} \times \mathrm{sec}^{-1}$ for the half-space. The $\mathrm{v}_{\mathrm{p}} / \mathrm{v}_{\mathrm{s}}$ ratio recalculated by the Wadati method and found equal to 1.76 . For each seismological station, time corrections were calculated, and thus lateral heterogeneities of the Earth's crust were indirectly taken into account, following a procedure with successive iterations until the changes in the calculated corrections became stable (e.g., Karakostas et al. 2012). The HYPOINVERSE computer code (Klein 2000) was also used for this relocation.

Figure 4a shows the relocated aftershock epicentral distribution, which is expected to reveal geometrical structure details not resolvable using the initially located (bulletin) seismicity. The diffuse aftershock cloud to the northeast of the mainshock epicenter is not present and the distinction between the aftershocks that occurred close to the main rupture with the isolated western cluster became pronounced. The spatial aftershock extent exhibits sharper boundaries and is slightly displaced in comparison with the initial catalog. To the west and near the mainshock epicenter, the aftershock distribution appears more sparse than in the remaining aftershock area, implying a possible location for the maximum co-seismic slip patch. Strike-normal vertical cross sections at the same locations and with the same width as previously are shown in Fig. 4b. The aftershock activity is now distributed at larger depths (mostly deeper than $3 \mathrm{~km}$ up to $15 \mathrm{~km}$ ), which seems more compatible with the extent of the seismogenic layer of the Aegean area, as previously mentioned. The cross-sections $\mathrm{P}_{3}$ and $\mathrm{P}_{4}$ provide clearer evidence of the northward fault dip, in good agreement with the one suggested by the GCMT solution, also

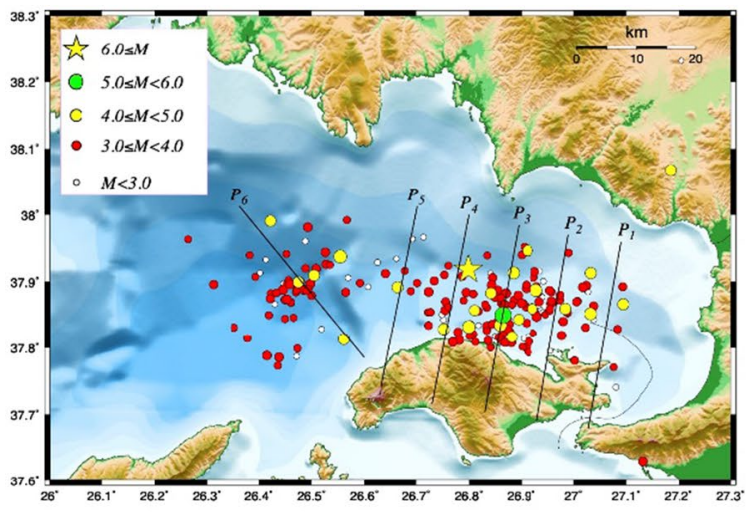

(a)

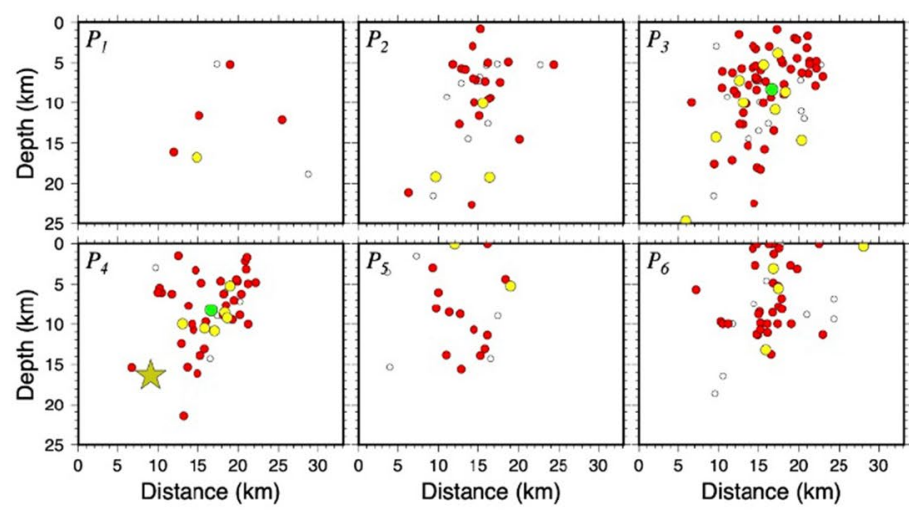

(b)
Fig. 4 a Relocated seismicity by the use of a local velocity model, corrected picks, and station corrections, along with a recalculated $\mathrm{Vp} /$ $\mathrm{Vs}$ ratio and improved relocation algorithms. b Aftershock depth dis- tribution along strike-normal vertical cross sections (surface projections are shown in Fig. 1a) 
shown in cross-sections $\mathrm{P}_{1}, \mathrm{P}_{2}$ and $\mathrm{P}_{5}$. The $\mathrm{P}_{6}$ section still suggests an almost vertical seismic zone, indicating a strikeslip character of the activated fault segment to the west of the main rupture. This tentative conclusion is found in good agreement with the fault plane solutions that were determined afterwards (Karakostas et al. 2021). It is important to notice that the previously described relocation procedure is practically semi-automatic: While some parameters can be controlled by the analyst to optimize the relocation on the basis of the data characteristics (e.g., distance to closest seismological station, azimuthal gap, etc.), it is clear that its application can be practically automatized, providing reliable information on an aftershock sequence, such as the one of the M7.0 2020 Samos mainshock.

\section{Spaceborne imaging geodesy}

Since the initial development of spaceborne synthetic aperture radar (SAR) systems and the demonstration of the SAR interferometric capability, the technique has reached its maturity for the detection of earthquake-induced ground displacements (Cornou et al. 2020; Bacques et al. 2020), among other geohazards (Delgado Blasco et al. 2019; Papageorgiou et al. 2019; Aslan et al. 2020; Cigna and Tapete 2020; Vassilakis et al. 2020). In the last decade, Earth Observation (EO) satellite missions are providing a richness of data at improved spatial resolution and coverage, as well as reduced revisit time, while the latest generation of SAR sensors ensures the millimeter precision of interferometric measurements (Gisinger et al. 2019).

Nowadays, there are many opportunities to advance the use satellite-based Earth observations for rapid response to geohazards. These opportunities are now possible due to the initiatives of the space sector, which has been developing an unprecedented Earth Observation infrastructure, in particular the Copernicus Sentinel constellation of satellites (Aschbacher and Milagro-Perez 2012). At the same time, platform-based solutions offer access to data and algorithms for massive DInSAR processing (Morishita et al. 2020; NASA Disasters portal, https://maps.disasters.nasa.gov), whereas others also provide thematic exploitation and e-collaboration capabilities (Foumelis et al. 2019).

The ever-increasing volume of satellite data (Sentinel-1 being a very characteristic case of large-volume data), as well as the outcome of discussions during scientific consultations (Bally 2013) revealed the need for cloud-based processing solutions, such as the GEP, to address difficulties of both storage and processing capacity. The impact of such state-of-the-art infrastructures is of significant importance towards the generation of timely EO results and as a consequence the rapid response to geohazards events.

\section{Rapid DInSAR measurements}

Our area of interest (AOI) is located in Europe, which based on the Sentinel-1 observation scenario, hence it is covered every 6-days by both Sentinel-1A \& -1B satellites. This is an advantage when rapid response is intended. For regions outside Europe the acquisition strategy follows a 12-days repeat cycle, apart from some supersites (https://geo-gsnl. org) and other specific target areas, e.g., when volcanic eruption or earthquake occur. Based on the mission design, each region is "seen" by a minimum of two orbit configurations, an ascending and a descending one, that can reach depending on the geolocation of the AOI up to four orbits (two each acquisition geometry). In the case of Samos earthquake, the area is covered by two ascending (131 and 029) and a single descending track (036), of which two are acquired on the same day of the year at different times (see Table 2).

As already mentioned, the issue of rapid DInSAR solution is twofold and the availability of satellite imagery is only one aspect. Rapid data dissemination and processing mechanisms are equally impacting our response capacity. An exploitation platform such as GEP allows the minimization of efforts and requirements in terms of storage, computational power and tailored automatic processing chains. EO practitioners may simply run integrated services and directly obtained results for further analysis and interpretation. The synchronization of the platform to the mission catalogs and other dissemination portals is of critical importance to avoid introduction of delays.

Within the first $24 \mathrm{~h}$, we exploited the capability of GEP by generating co-seismic displacement maps utilizing different on-demand services, namely the SNAP DInSAR (based on ESA SNAP toolbox; http://step.esa.int/main), the CNES DIAPASON (part of OTB open-source project; https://www.orfeo-toolbox.org) and the CNR-IREA P-SBAS (Casu et al. 2014; Manunta et al. 2019), using the proposed default parameters and controlling only the spatial resolution of the outputs (Fig. 5). The ascending scene (track 131)
Table 2 Information on the achieved and planned Copernicus Sentinel-1 mission data during the early response phase of the Samos earthquake

\begin{tabular}{llllll}
\hline Acquisition geometry & Relative orbit & $\begin{array}{l}\text { Incidence } \\
\text { angle }\left({ }^{\circ}\right)\end{array}$ & $\begin{array}{l}\text { Acquisition } \\
\text { time }(G M T)\end{array}$ & Pre-seismic dates & Post-seismic dates \\
\hline Ascending & 131 & 33.94 & $\sim 16: 06$ & $18 / 10,24 / 10$ & $30 / 10,05 / 11$ \\
Descending & 036 & 39.25 & $\sim 04: 15$ & $18 / 10,24 / 10,30 / 10$ & $05 / 11$ \\
Ascending & 029 & 43.95 & $\sim 16: 15$ & $23 / 10,29 / 10$ & $04 / 11$ \\
\hline
\end{tabular}



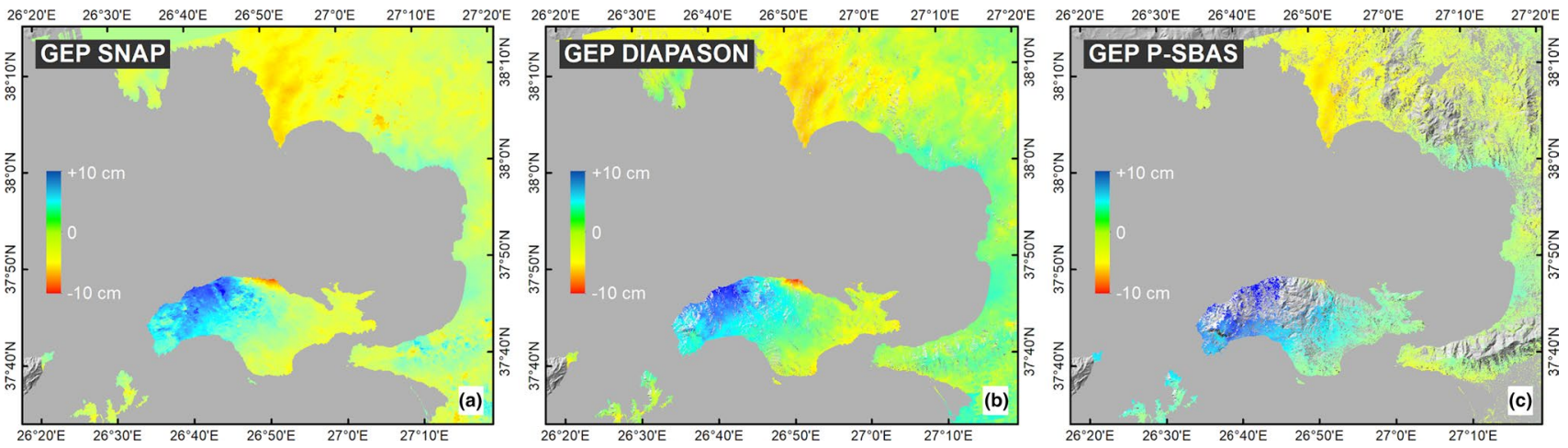

Fig. 5 Sentinel-1 co-seismic LoS ground displacements of the M7.0 Samos earthquake. The processing was executed on GEP using a SNAP, b DIAPASON and c P-SBAS services within $24 \mathrm{~h}$ after the event, on the same day as the earthquake and less than $12 \mathrm{~h}$ apart. As illustrated, interferometric measurements appear aligned showing a sinking pattern (up to $-9 \mathrm{~cm}$ ) concentrated along a narrow area at the northernmost part of Samos (Agios Konstantinos-Vourliotes region), whereas the W-NW part of Samos island shows significant uplift (reaching locally $12 \mathrm{~cm}$ ). Contains modified Copernicus Sentinel-1 mission data, processed by AUTh on GEP was acquired $\sim 4 \mathrm{~h}$ after the earthquake, serving the optimum mapping of co-seismic displacements. In addition to considering only the temporarily closest acquisition prior to the event (6-days span), we also used the 12-days co-seismic pair to investigate potential contribution of error sources (e.g., atmospheric signal) and in the meanwhile allow the inter-verification of our findings.

DInSAR measurements are tied to a local reference area, often arbitrary selected to an assumed stable region during processing. As a consequence, this reference highly affects the magnitude and the sign of motion delivered. In our case, the airport area located at the southeastern part of Samos was selected.

During this initial phase, DInSAR provided accurately geocoded motion estimates along the line of sight (LoS) of the satellite, outlined the area affected by measurable co-seismic motion, regions of secondary ground displacement phenomena (i.e., slope instabilities) and information on whether the rupture reach, or not, the surface. Based on those observations, the northeastern part of Samos undergoes co-seismic uplift reaching $12 \mathrm{~cm}$. The uplift pattern appears to be spatially homogeneous (no abrupt changes), increasing towards the NW. A local downlift pattern (up to $-9 \mathrm{~cm}$ ) also dominates the northern coastal zone from Agios Konstantinos to Kokkari. Both patterns are separated by a zone of zero deformation (based on the selected local reference), trending approx. WNW-ESE.

Among the first $24 \mathrm{~h}$, DInSAR limitations concern mainly the inability to properly compensate for atmospheric contributions and the use of restitute orbit state vectors. Thus, visual interpretation is still required to identify such uncompensated signals and decide on the usability of the specific interferometric pair. Furthermore, restituted orbits (approx. $10 \mathrm{~cm}$ accuracy) are delivered within few hours from sensing, compared to the 20-days latency of precise orbits (better than $5 \mathrm{~cm}$ accuracy in 3D) (Peter et al. 2017); however, in terms of rapid response requirements and the magnitude of motion involved, this is more than sufficient, introducing only subtle inaccuracies to the interferometric phase measurements.

\section{Multi-temporal DInSAR observations}

In less than a week from the main event, three additional Sentinel-1 scenes were acquired (Table 2). These images are independent datasets by which indirect validation of the DInSAR observed displacement field is possible (Fig. 6). At this stage, it is important to keep in mind that deviations may be related to the differences in time span (i.e., contribution of post-seismic motion), acquisition geometry and incidence angle between the observations. For this subsequent investigation processing was performed using the GAMMA software packages (Wegnüller et al. 2016), via a semi-automated chain (Papageorgiou et al. 2019) running on a Virtual Machine, provided by ESA's RSS-CloudToolbox infrastructure (Marchetti et al. 2012), having direct access to the Sentinel-1 archive of the Data and Information Access Services (DIAS) repository (specifically the CREODIAS; https://creodias.eu). Figure S1 shows the entire number of generated differential interferograms.

The temporal distribution of Sentinel-1 acquisitions permitted the separation of post-seismic motion during the first 4-5 days (Fig. 7). For this period, cumulative uplift over the previously affected area (NW of Samos) is of the order of 3-4 cm, whereas no downlift signal is observed along the northern coastal zone. The presence of post-seismic deformation confirms our primary choice not to proceed with averaging of subsequently generated co-seismic interferograms (e.g., by stacking approach) to improve the co-seismic 

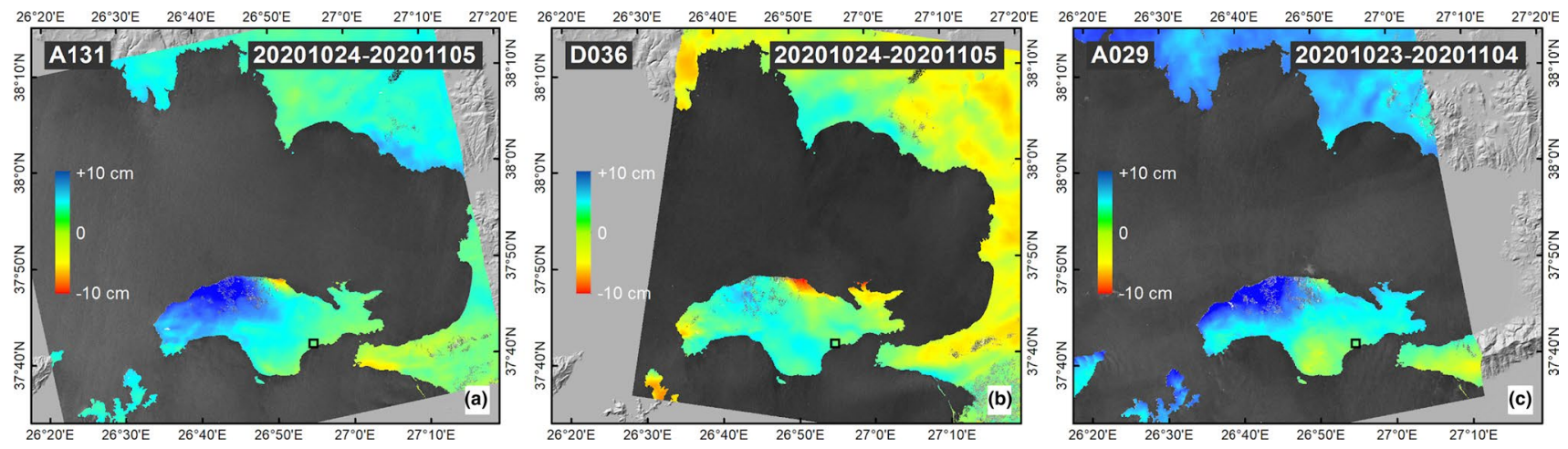

Fig. 6 LoS ground displacements derived by interferometric processing of Sentinel-1 post-event data, acquired up to 5 days after the earthquake. Positive LoS values correspond to motion towards the satellite, whereas negative to motion away from the satellite, consisted with uplift and downlift, respectively, if horizontal motion (mainly in E-W direction) is assumed negligible. Motion variability is due to differences in acquisition geometry and incidence angles. Local reference area is shown as black square. Contains modified Copernicus Sentinel-1 mission data (2020) estimates. This means that co-seismic DInSAR results cannot actually be refined during this rapid response phase.

Finally, having observation from different angles permits the decomposition of motion into actual vertical and E-W components (Fig. S2). This is a more familiar motion representation for non-EO practitioners. It is worth noting that $\mathrm{N}-\mathrm{S}$ motion component cannot be addressed using only DInSAR. Those measurements can be easily compared to GNSS data, constraint further simulation and modelling efforts and serve as inputs for better interpretation of observations from other domains.

\section{Global navigation satellite system}

\section{GNSS observations}

The investigation and analysis of the Samos earthquake through global navigation satellite system (GNSS) were carried out on the basis of several datasets from different sources in Greece and Turkey. More specifically, Metrica S.A. kindly offered data for the SAMO station, which belongs to the HxGN Smartnet (https://hxgnsmartnet.com). Measurements from the Turkish stations were released by the Turkish National Permanent RTK Network (TUSAGA) (https://www.tusaga-aktif.gov.tr). As registered users, we were also able to access data from the Hellenic Cadastre network (HEPOS, https://www.hepos.gr) and the Uranus Network (operated by the Tree Company; http://www.uranus.gr), since both datasets are not publically available, even for early response work related to geohazards. Details on the timely availability of each of the GNSS station data are shown in Table S1.

Fortunately for Samos, compared to other Greek islands, there are three GNSS stations installed, which allow proper investigation of co-seismic motion. The SAMOS station is located near the earthquake's epicenter, while stations 093A and SAMOS at the southern and northeastern part of the island, respectively. However, SAMO station was unexpectedly shut down during the period October 30th-November 1st (11:52 GMT), hampering any high frequency near-field investigation. On the contrary, stations 093A and SAMOS are the only stations that operated with a sampling rate of one second.

\section{GNSS data processing}

We exploit the Precise Point Positioning (PPP) method (Zumberge et al. 1997) for geodetic data processing. This is a single-point technique, which utilizes the zero differences of the station to numerous GNSS satellites. Its main advantage lies on its independence from differential positioning technique. In general, it provides accuracies at the centimeter level (Alkan et al. 2020). Furthermore, in contrast to the GNSS-campaign results, PPP allows continuous monitoring at near-real time.

All the PPP computations were accomplished through the CSRS-PPP service (https://webapp.geod.nrcan.gc.ca/geod/ tools-outils) of the Natural Sources of Canada (Grinter and Janssen 2012; Natural Resources Canada 2019). Processing on such platform facilitates solutions with accuracies sufficient for the rapid investigation of earthquake events. This significantly minimizes the handling of GNSS data, ensuring outputs at well-defined formats for which visualization and other post-processing services could be built upon.

\section{Rapid GNSS solution}

We first proceed with the most rapid response, which focuses on the monitoring of the stations' position deviations seconds before and after the event. For the implementation of 

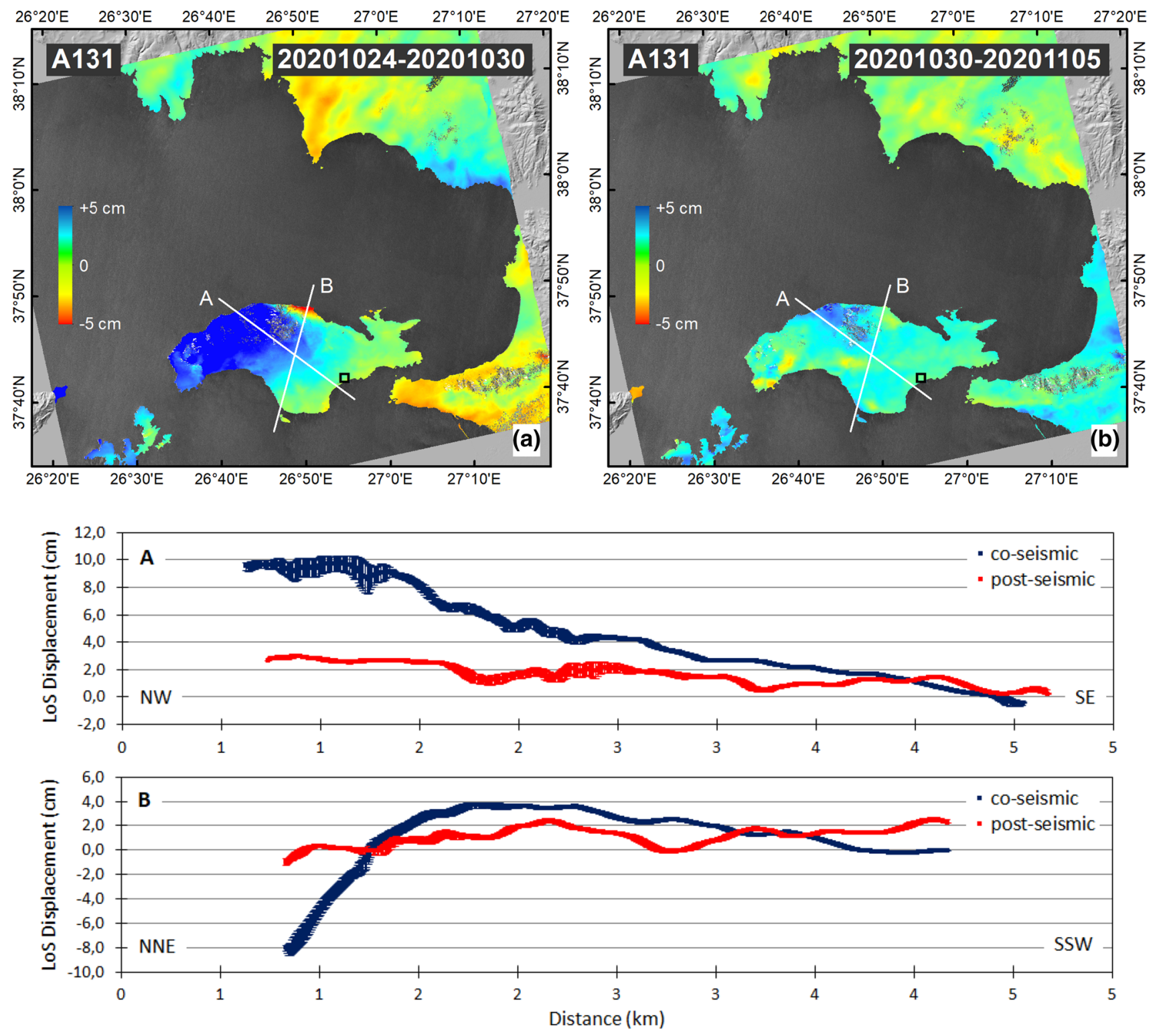

Fig. 7 DInSAR ground displacements along the LoS for a the coseismic and $\mathbf{b}$ the post-seismic (first 5 days) periods. Local reference area is shown as black square. Local reference area is shown as black square. Spatial profiles (A and B) show the variability of motion.

this initial response, we use the ultra-rapid GNSS orbits for the day after the earthquake (31st of October), with an accuracy of approx. $3 \mathrm{~cm}$ and a latency of 3-9 h (https://www. igs.org). We quantify the coordinate changes in terms of Universal Transverse Mercator (UTM-Zone 35) projection coordinates and the WGS84 ellipsoidal height.

The rapid responses of stations 093A and SAMOS are shown in Figs. 8 and 9, respectively, where we observed significant deformation after the event. For station 093A, we find maximum values of $9 \mathrm{~cm}$ at the East-West, $-16 \mathrm{~cm}$ at the North-South and $5 \mathrm{~cm}$ at the Up-Down directions, respectively. As for station SAMOS, the corresponding
The NW part of Samos is still deforming with a cumulative motion of about 3-4 cm during the following 5 post-seismic days. Local reference area is shown as black square. Contains modified Copernicus Sentinel-1 mission data (2020)

measured values are $-10 \mathrm{~cm}$ for the East-West, $-9 \mathrm{~cm}$ for the North-South and $5 \mathrm{~cm}$ for the Up-Down direction, respectively. We observe that the deformation starts, as expected, a few seconds after the earthquake, due to the time required for the propagation of motion from the source to the GNSS station. We also point out the sign difference between the two stations, regarding the East-West direction. Additionally, a quasi-periodic motion of the height component can be observed. Unfortunately, during this initial response phase, no measurements were available from the SAMO station, the station closest to the epicentral area, as previously mentioned. 

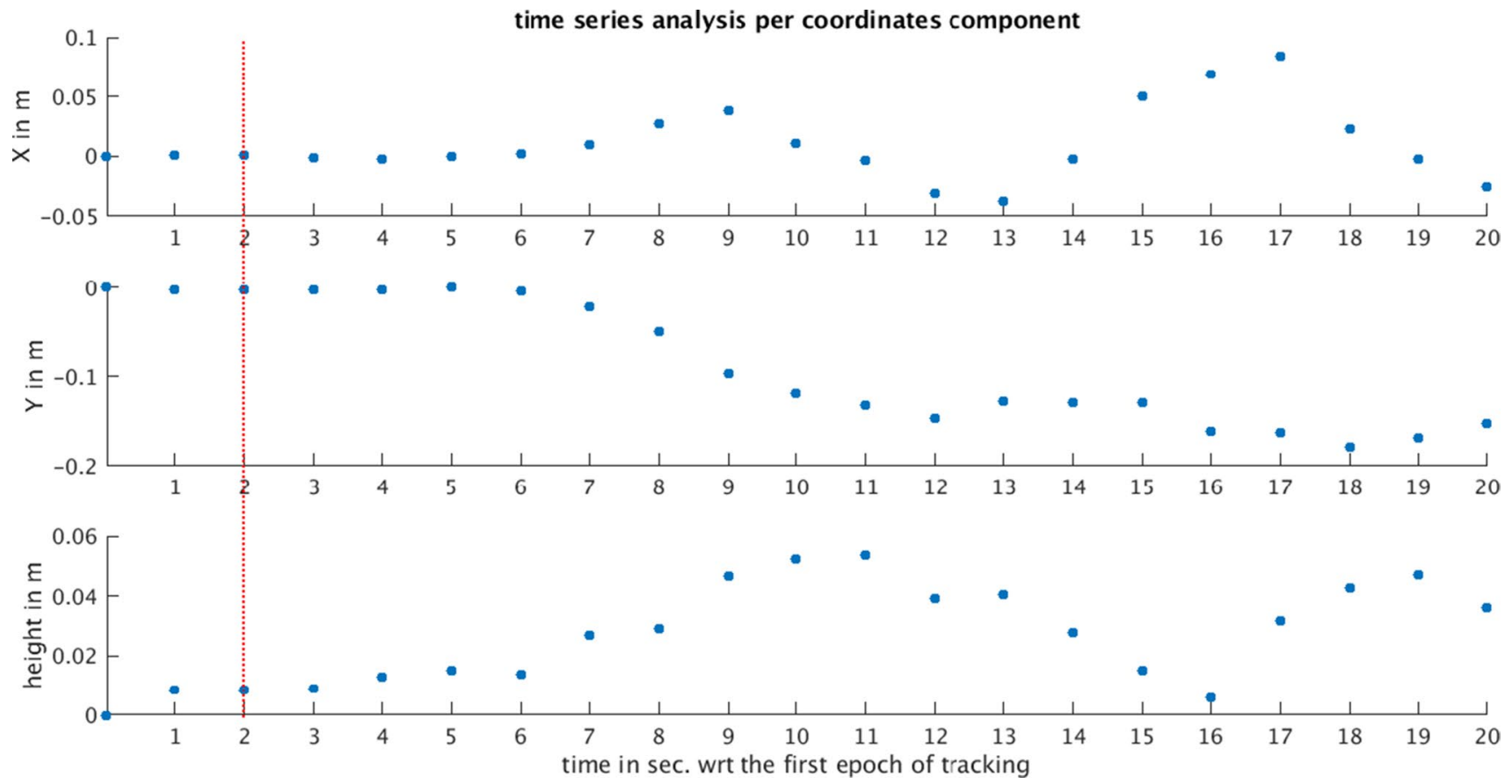

Fig. 8 Time series per coordinate component for GNSS station 093A showing the rapid response during the Samos earthquake. The red approx. 6-7 s after the event is depicted. Temporal motion pattern line refers to the time of the earthquake. Co-seismic motion recorded

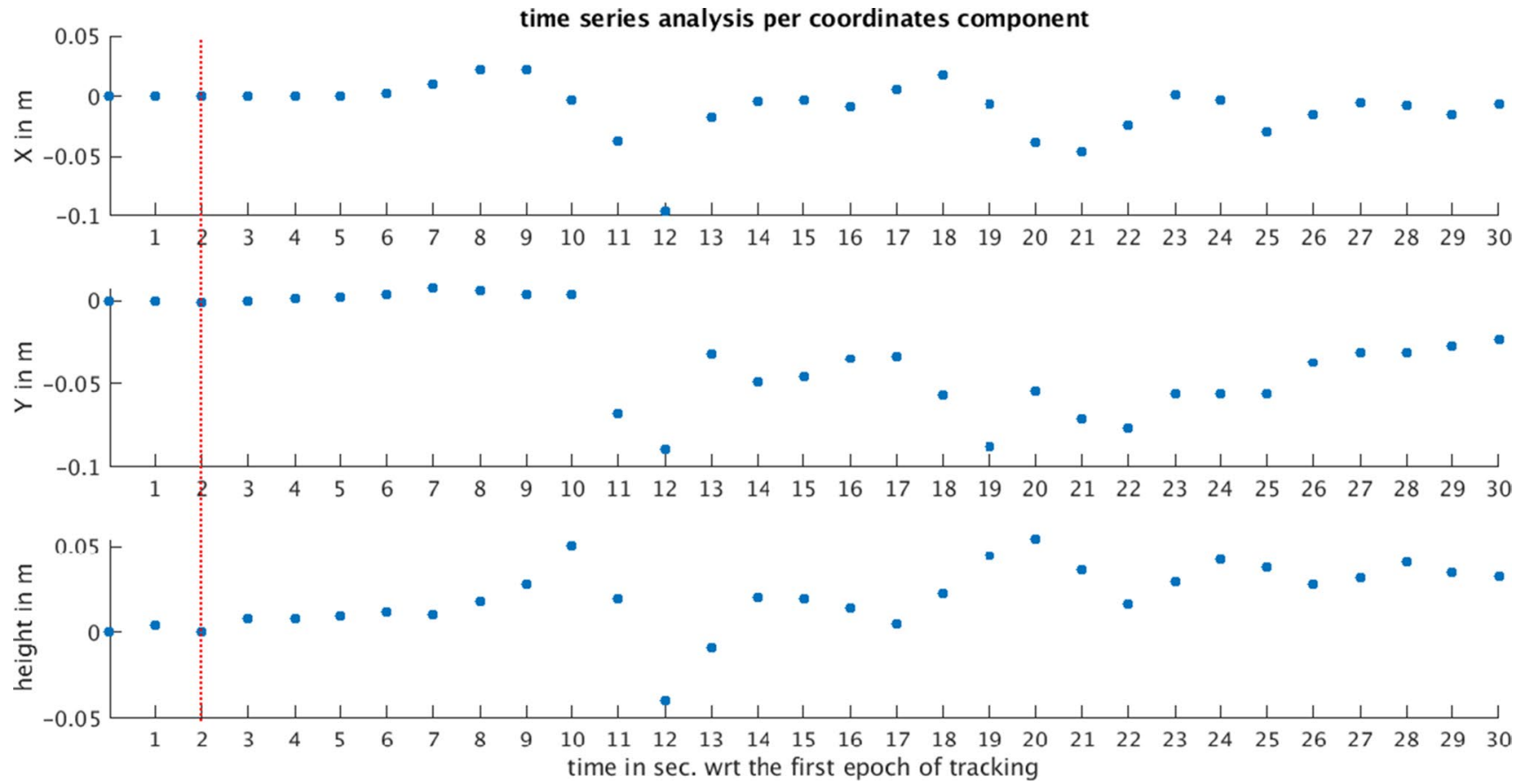

Fig. 9 Time series per coordinate component for GNSS station SAMOS, showing the rapid response during the Samos earthquake. The red line refers to the time of the earthquake. Similarly to 093A station (Fig. 8) motion recorded few seconds after the event is shown. Fluctuations are observed in all motion components during the evolution of the phenomenon 


\section{Refined GNSS solution}

In addition to the rapid response efforts, we studied the 3D displacement of an extended area using daily RINEX files of various stations and using the GNSS updated orbits. These final orbits are the most accurate ones $(\sim 2.5 \mathrm{~cm})$ and they are released with a 12-18 days latency.

The deformation analysis allows us to assess the earthquake impact in terms of 3D spatial changes. We compare the coordinate differences of 14 stations, one day before (October 29th) and three days after (November 2nd) the event (Table S1). For this comparison, we have computed the daily positions using $24 \mathrm{~h}$ of observations (except for SAMO on the 2 nd of November, for which we have $12 \mathrm{~h}$ ). The derived horizontal displacement vectors from GNSS are shown in Fig. 10.

Due to the limited observations available from the SAMO station (data missing for about 3.5 days); we choose to investigate the distortions of the network using all available stations. The overall 3D accuracy of the GNSS displacement measurements was calculated to be of the order of $1 \mathrm{~cm}$.

The results from Fig. 10 show that highest displacements were observed at the SAMO station, nearest to the epicenter, namely $-37 \mathrm{~cm}$ and $-6 \mathrm{~cm}$ in North-South and
East-West directions, respectively. In addition to horizontal motions, the displacement in the vertical direction is also rather high, reaching $+9 \mathrm{~cm}$, a clear evidence of postseismic uplift. The slight spatial variability of GNSS coseismic vectors at $093 \mathrm{~A}$ and SAMOS station compared to the location of the main event, might imply a non-homogeneous behavior, however, it is clear that the northwestern part is the most affected (concerning static displacements) compared to the rest of the island. Co-seismic displacements at Cesme and Izmir (Turkey) are of the order of $3-5 \mathrm{~cm}$ in the horizontal plane, whereas for other Greek islands (i.e., Leros, Ikaria, Chios and Mykonos) vary in the range of $1-5 \mathrm{~cm}$.

A direct comparison between cumulative vertical motion at SAMO station from GNSS $(+9.0 \mathrm{~cm})$ and DInSAR $(+9.7 \mathrm{~cm})$, five days after the event, indicate differences within the error limits of the employed techniques. The consistency between those independent measurements is also clearly noticeable from the spatial interpolation of GNSS data (Fig. 11). However, it should be noted that the continued spatial coverage of surface displacements obtained from EO data, allowed to detect the small (regarding its spatial extent) but significant downlift at the northern part of Samos, something not possible with the density and distribution of a regional GNSS network.
Fig. 10 Co-seismic displacements based on daily observations at 14 GNSS stations. Data visualized on Bing Maps (accessed in QGIS)

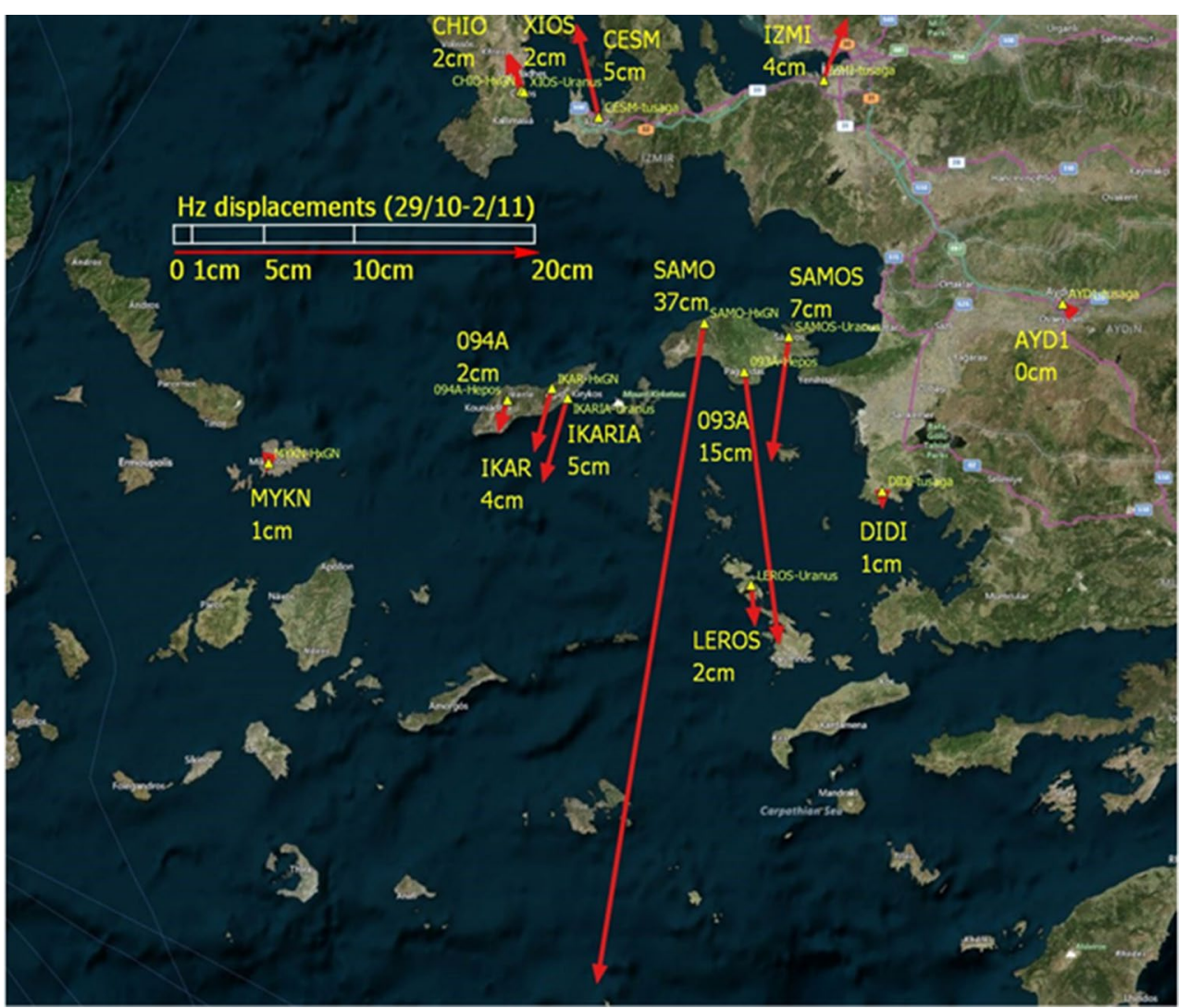




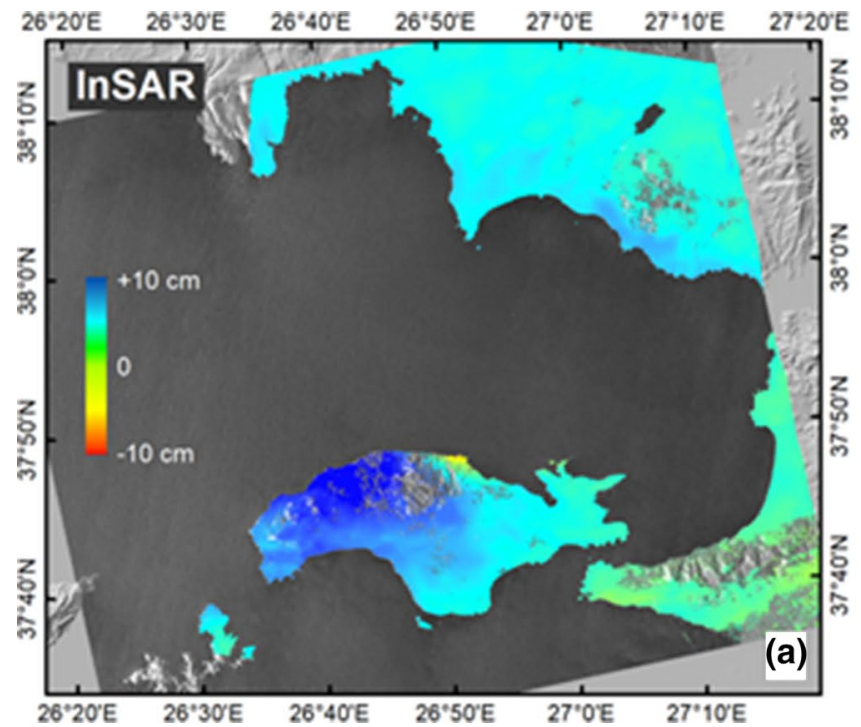

Fig. 11 Actual vertical ground motion component by a DInSAR and b GNSS measurements, corresponding to cumulative displacements including co-seismic and 5 day of post-seismic motion (up to November 5, 2020). Local reference area is shown as black square. The fault zone (dashed line) from the NOA v3.0 fault database (Ganas et al.

\section{Fault modelling}

Generating an approximation of the fault whose motion triggered the quake is crucial for understanding the stress release and surface processes. The modelling procedure uses a combination of retrieved seismological and/or geodetic measurements in an inverse algorithm in attempt to define the fault geometry. For this study case, the fault geometry is simplified to a single rectangular source described with nine parameters following the Okada (1985) concept—fault length, fault width, depth of the upper fault edge, strike angle, dip angle, rake angle, uniform slip, and shifts in the northern and eastern direction between the top center of the fault and the earthquake epicenter. Within this study, we show several fault modelling scenarios, depending on the information provided by rapid response and the available data from different disciplines previously described. It is important to note that these solutions do not represent the best-fitting models but the fastest answers within the required time spans of this study. We took into account not only the times of acquiring the data-geodetic and seismological, but also the processing time required for generating the models; i.e., to achieve the best-fitting models more time-consuming iterations are needed.

\section{Modelling procedure}

In order to optimize the parametrization of the fault geometry and dislocation with a minimum misfit between observed

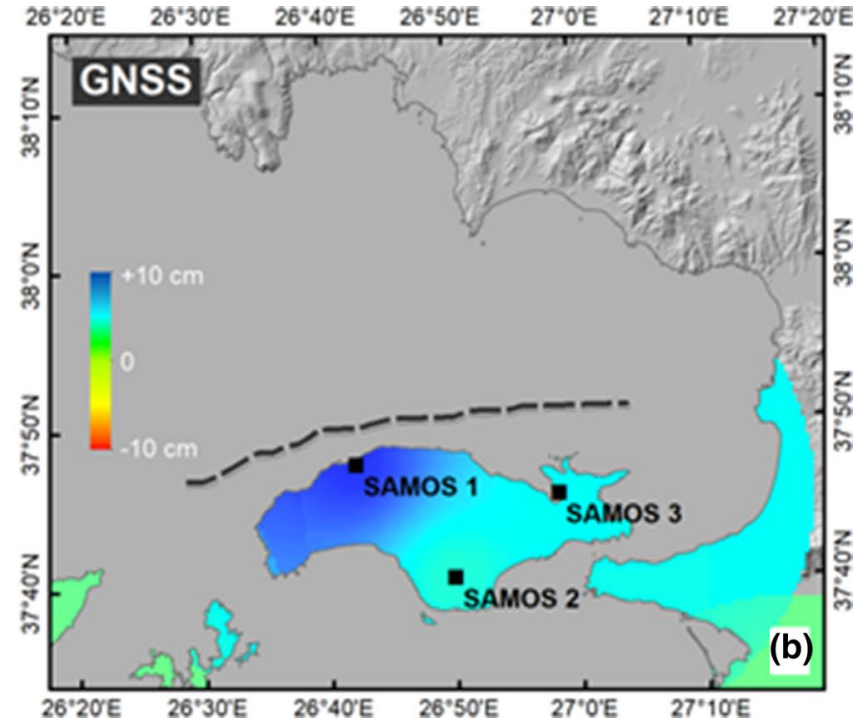

2018) was used to constrain the extrapolation of GNSS data to the North. An overall agreement between independent geodetic observations for the NW part of Samos is observed; however the downlift motion at the northern coastal zone of Samos is not detected by the GNSS data, due to their limited spatial coverage

and synthetic data in an L2-norm manner, a Bayesian bootstrap-based probabilistic joint inversion has been employed in the GROND framework (Heimann et al. 2018). The inputs for the procedure are DInSAR displacement maps and/or GNSS displacement vectors. The post-processing of the DInSAR co-seismic displacement map derived as SNAP output includes: the configuration of the spatial quadtree subsampling (Jónsson et al. 2002), the computation of data covariance matrix and the modelling of the Okada static displacement source. The KITE software (Isken et al. 2017) was used for these steps. The covariance quantifies the contribution of noise to the SAR signal, while the subsampling ensures the efficient forward modelling. The latter is performed as follows: the DInSAR scene is split into four quadrants, and then the displacements in each quadrant are averaged and compared to a pre-defined root mean square (rms) threshold. If the mean value is bigger than the threshold, a further division is performed. In this study case, the rms threshold of 0.1 along with a minimum tile size of 0.01 was deemed appropriate to achieve a number of samples that is an effective representation of the real displacement scene and is also computationally effective.

The parameters optimization with GROND is performed in three stages. During the first stage, the models are drawn randomly - in this case for 5000 iterations. Next, specific models are injected for a new series of optimization-the selection is based on a multivariate normal distribution defined by the covariance and the scale of the search factor applied to the models from stage 1 with the lowest misfit. 
The scaling factor was chosen to be 1.5 at the start of the stage, decreasing logarithmically to 0.5 at the end $(55,000$ iterations in total). Finally, the uncertainties to the fault model were realized by 200 parallel bootstrapping chains (Daout et al. 2020), applying perturbations from synthetic random noise for the InSAR data and from measurement uncertainties for the GNSS data.

For the forward calculation of the synthetic static surface displacements, the velocity model of Akyol et al. (2006), used previously for the aftershocks relocation (see Sect. 3.1), was adopted for the computation of the Green's Functions using the PSGRN/PSCMP backend (Wang et al. 2006). The latter is implemented through the FOMOSTO tool included in the PYROCKO framework (Heimann et al. 2018), which contains also the previously used KITE and GROND packages.

\section{Modelling strategies}

As earlier described, the aim of the present study is to demonstrate the capacity of solving the rapid response after a particular significant seismic event taking into account the available data within chosen timespans. Four variants of fault optimization were performed based on the availability of co-seismic DInSAR displacement map and GNSS-derived displacements (Table S2). We adopted the GCMT moment tensor solution (see Sect. 3.1) as a reference.

In all four versions, the co-seismic ascending pair from orbit track 131 was used. The second image of this interferogram is acquired just several hours after the mainshock resulting in minimum post-seismic displacements and aftershocks contribution. We formulated the Model No1 based only on these spatial geodetic data. Taking into account that during the first $24 \mathrm{~h}$ the seismological data (earthquake locations, revised moment tensor solutions) were insufficient, we implemented very loose constraints for the fault dimensions, assumed a uniform slip and a fault position constrained by the epicenter, while the strike, dip and rake angles were left unconstrained. The comparison between the original co-seismic DInSAR-derived displacements (a), and the resulting forward displacement model presented in $\operatorname{LoS}(\mathrm{b})$, as well as the corresponding residuals are presented in Fig. 12.1. The figure also includes the mean values of the fault parametrization (also presented in Table S3). For the second model, we used the same setting as for the first one, but we also included the refined 24-h solution of the GNSS displacement vectors (without the SAMO station)—-see Fig. 12.2 and Table S3 for the results.

For the Model No 3, we employed the settings of Model 2 but this version used narrowly defined ranges for the searching algorithm constrained after a north-dipping fault was suggested by the relocated aftershocks (Sect. 3.1) and the GCMT solution: between 240 and $300^{\circ}$ for the strike, 20 to $55^{\circ}$ for the dip angle and -120 to $-60^{\circ}$ for the rake angle, and refined with about $30-40 \%$ ranges of the fault dimensions and depth. The results are shown in Fig. 12.3. The 12-h solution of the co-seismic displacement of the closest GNSS station SAMO is included in the input data set for the Model No 4. Even though the GNSS measurements were used together with DInSAR in the generation of Models 2, 3 and 4, the comparison between the measured and modeled GNSS displacement vectors are presented in a separate figure (Fig. 12.4) due to the difference in spatial range of the DInSAR and GNSS data.

For each model under consideration, we determined the seismic moment using $\mathrm{Mo}=\mu \mathrm{AD}$, where $\mu$ is a shear modulus of $33 \mathrm{GPa}, \mathrm{A}$ is the fault area and D is the uniform slip of each model. The moment magnitude for each model is $\mathbf{M}_{\mathrm{W}}=2 / 3 \cdot \log 10$ (Mo)-10.7 (Hanks and Kanamori 1979)the results for the four models are shown in Table S3. A comparison between the observed and modelled displacement vectors in the locations of the GNSS stations for Models No 2, 3 and 4 are presented in the supplementary materials (Fig. S3). The optimization level of each parameter for the four models throughout the iteration process is presented in Figure S4 together with the mean values.

The comparison between the four proposed solutions revealed a significant difference between the model constructed only on DInSAR input and those which include also GNSS data. The purely DInSAR-based unconstrained Model (No 1) proposes south-dipping fault, while the other three fault models give a north-dipping solution which is in agreement with the relocated aftershock sequence (Fig. 4). Also, the Moment magnitude is underestimated for the first Model case. On the other hand, in all cases, the fault position is similar and a sinistral strike component (rake $-60^{\circ}$ ) exists for the fault slip in every model. The last model which also includes data from the closest to the epicenter GNSS station, results in a $\mathrm{Mw}$ estimate closer to the $\mathbf{M}=7.0$ reported by most of the seismological agencies, and indicate better agreement between the observed and modelled displacement vectors (Fig. S3.4). For the last model, a high dispersion is observed for some of the fault parameters such as length and slip, but also the difference in the scales must be taken into account. Further optimization, e.g., by including waveforms, introducing a variable fault slip pattern, or confining to the complicated local system of parallel faults instead of the assumed initial normal fault, would require much more iterations and accordingly time, and are not of interest (and currently feasible) for the rapid response phase.

\section{In situ observations}

Post-event screening observations were carried out on the northeastern coastal region from Vathy to Kokkari and the southeastern coastal region from Pythagoreion to Ireo in 
Fig. 12 Comparison between fault models, created for the different time and data-dependent solutions - the numbers in the lower right corners correspond to the modelling strategy listed in Table $\mathbf{S} 2 ; \mathbf{a}$ is the observed DInSAR co-seismic displacement calculated from the pair 24-30/10/2020 ascending Sentinel-1 scenes from orbit 131; b modelled displacement after parameters iterations (the best-fit values are shown) with the mechanism solutions; $\mathbf{c}$ residuals between observed and modelled displacement. The color scale shown in 1.c is valid for all images
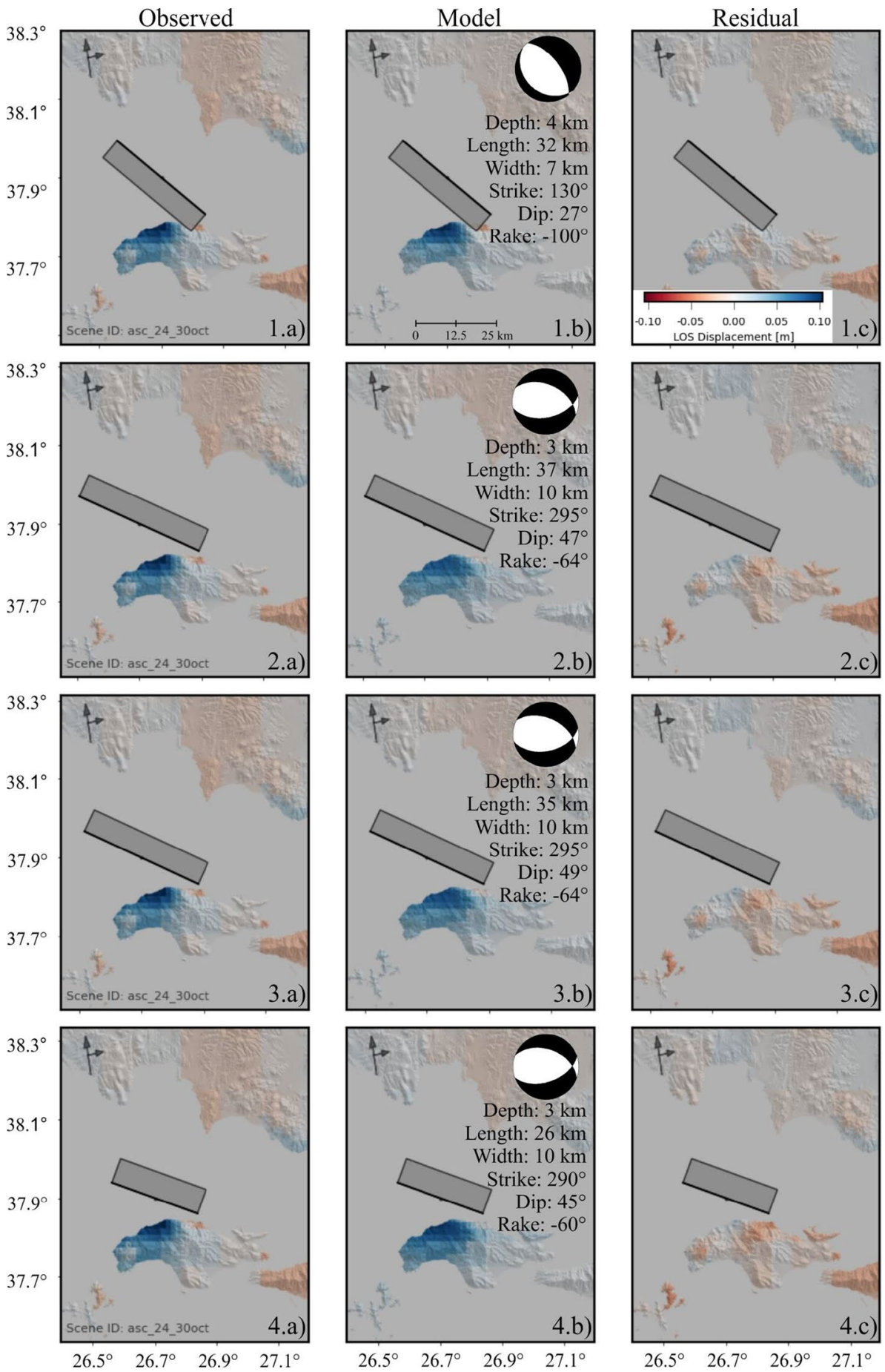

search of Earthquake Environmental Effects (EEEs) for preliminary ESI-07 intensity assessment at local level (Fig. S5). During fieldwork, several limitations affected accessibility, e.g., weather unfavorable in terms of strong wind conditions (NNE, 5-7Bf). As a result, the northern coastal region was characterized by high wave amplitude, hence unsuitable conditions for the examination of co-seismic uplift. In the southern region of the island, although the wave amplitude was low, a potential existence of wind seiche (sea level depression up to $5 \mathrm{~cm}$ according to the locals) could not be ignored. In addition, due to the development of the tsunami at the north of the island, it is not clear to what extent it has contributed to or triggered the development of EEEs and damages in coastal harbor structures.

In general, the Vathy and Kokkari harbor structures exhibited considerable damages indicative of liquefaction origin processes. The Malagari shipyard site, composed of Holocene coastal and alluvial deposits (Theodoropoulos 
1979), was dominated by EEEs, in the form of linear ground fractures and cracks in combination with sand boils and coastal subsidence, indicative of lateral spreading (Fig. 13). The recorded effects are distributed in a $3000 \mathrm{~m}^{2}$ area, and their characteristics (provided in Supplementary Information section) were correlated with the ESI-07 scale (Serva et al. 2015; Michetti et al. 2015) and are indicative of macroseismic intensity VII-VIII. However, it is not clear to what extend the effects represent exclusively ground shaking, since we cannot exclude the possibility be a result of the combination of ground shaking and tsunami effects.

The southeastern region of Samos, was not significantly affected by the earthquake. No diagnostic EEEs and no harbor structure damages were recorded. More specifically, along the Remataki coastal area located to the east of Pythagoreio harbor (Fig. 14a, a') and the Lykourgos Logothetis Castle coastal hill at the western end of Pythagoreio city (Fig. 14b, b', c, c'), the records (supplementary section) were supported by comparison of pre and post-event photo archives yielding no indications of co-seismic uplift. The lack of diagnostic EEEs observations corresponds to ESI-07 intensity of I-III (Michetti et al. 2015).
In summary, in terms of EEEs and harbor structures damages, field observations indicate an intensity of VII-VIII for the northeastern region of Samos. On the contrary, for the southeastern region, field observations indicate an ESI-07 intensity of I-III and do not support co-seismic vertical displacements along the southern coastal zone. The above observations are in agreement with the pattern of ground displacements as derived by DInSAR measurements, as well as the fault location. Detailed descriptions of field observation for several sites are provided in the Supplementary Information section.

\section{Results and discussion}

Similar to other natural phenomena, the study of earthquakes involves several disciplines of geosciences. In the case of the Samos earthquake, various research groups made considerable efforts to provide technical information and/ or preliminary interpretations based either on a single or a multidisciplinary approach. Their common objective was the rapid availability of scientific data and information concerning the seismic event in order to contribute towards a more
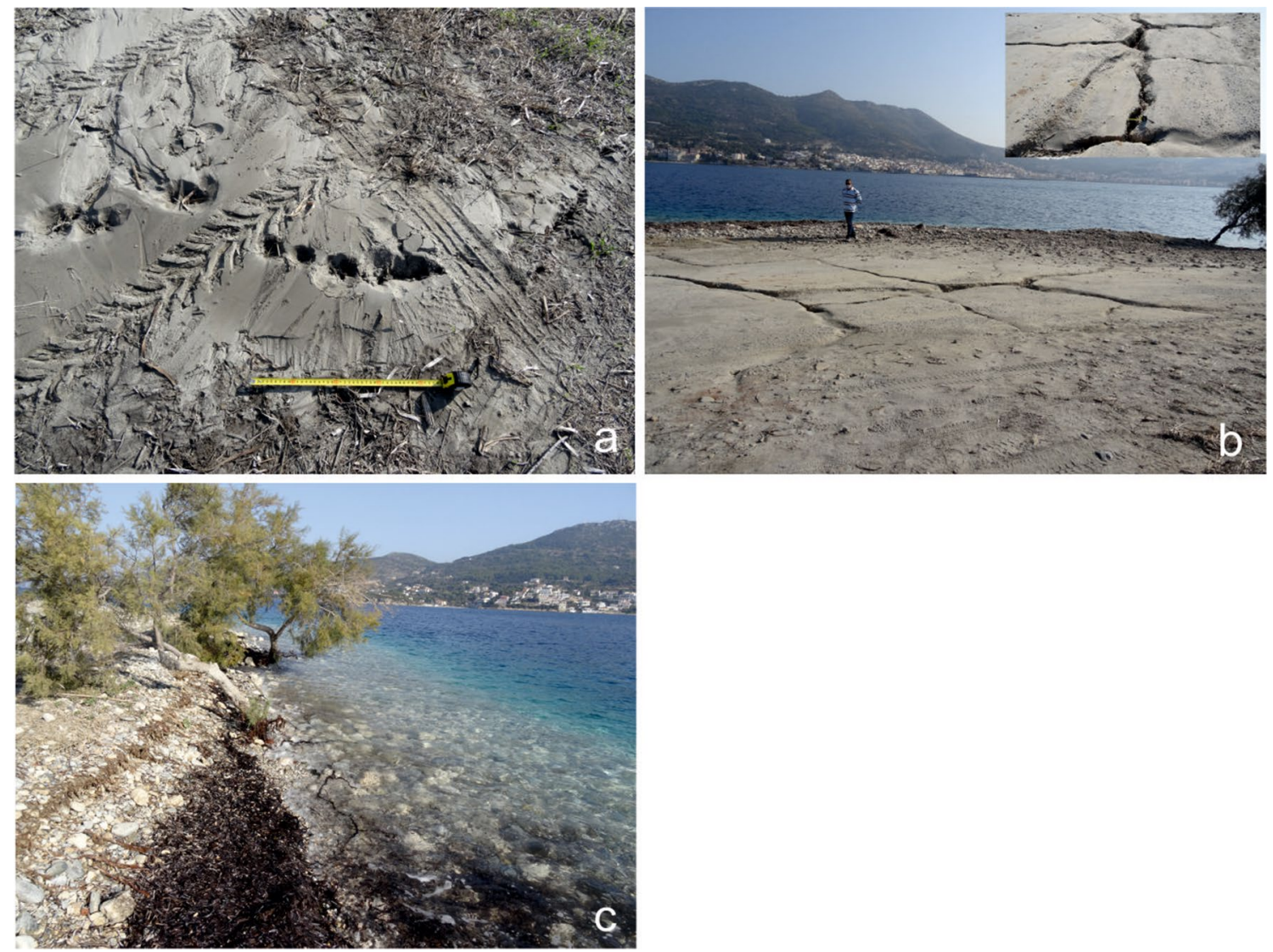

Fig. 13 Malagari shipyard site. a liquefaction sand boils, $\mathbf{b}$ lateral spreading fractures and $\mathbf{c}$ trend of coastal crack dip, subsided coastline and eradicated trees 

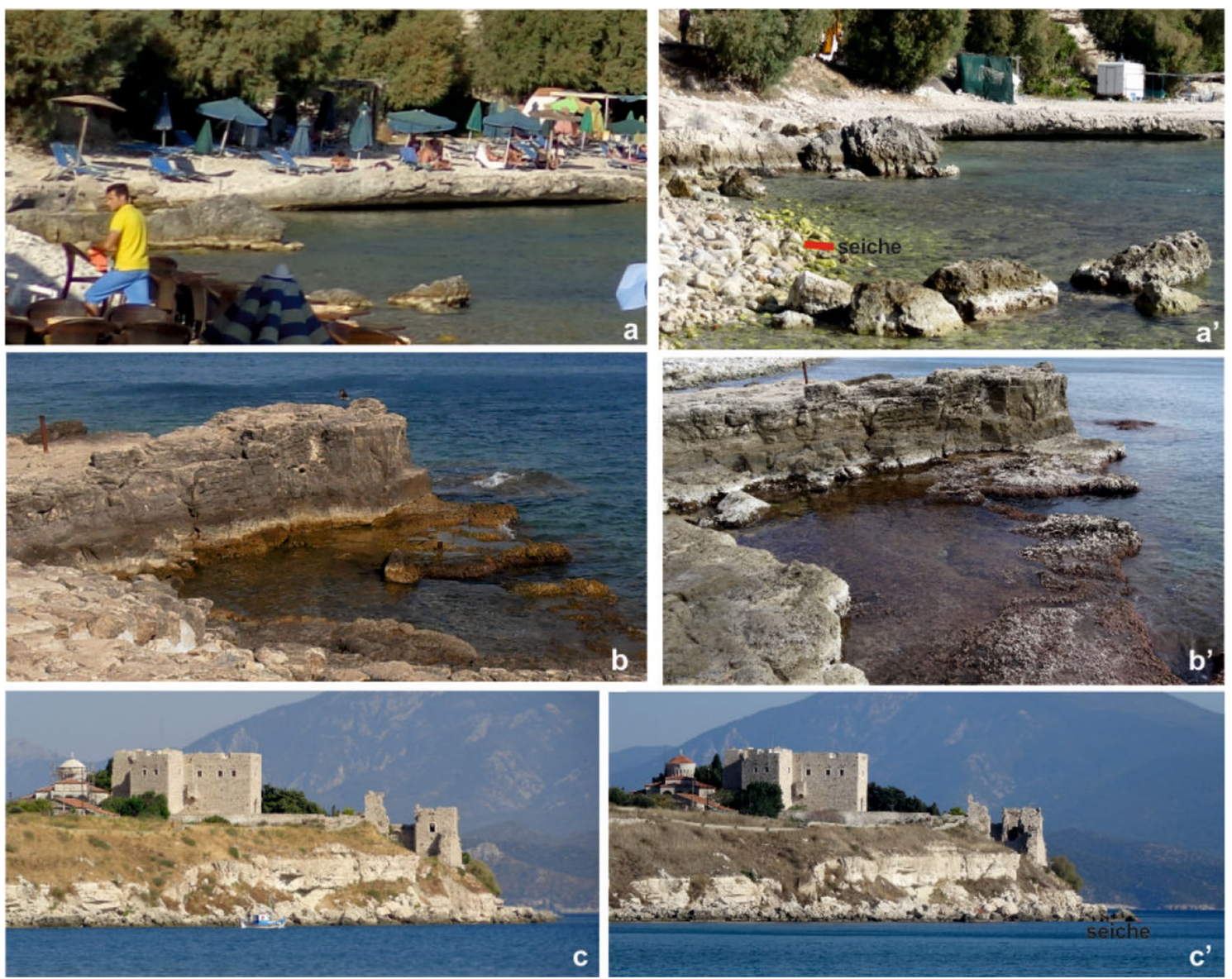

Fig. 14 Pre event photos (2013) to the left in comparison to post-event photos (2020) to the right with N-S trend (see text for details)

targeted response from local authorities as well as national institutions involved in capacity development for emergency management and disaster risk reduction.

In the current work, beyond the inter-disciplinary response to the phenomenon, we focus on the assessment of the timely provision of information by each science domain during the critical period of several days after the onset of the phenomenon. We evaluated both the access to primary data as well as the readiness level of the scientific community in terms of rapid data processing, within the constraints of each individual technique. Taking as a practical example the case of Samos (Kusadasi bay) region, an area of relatively high coverage by local networks, we discuss the level of response anticipated for future seismic events located in areas of less favorable monitoring condition (i.e., sparse seismological network, unavailability of GNSS, high latency of EO data, inability to acquire field observations).

For the Samos M7.0 earthquake, and after the approximate determination of the epicenter by various seismological centers, the main question at hand concerned its association with a specific ruptured zone, i.e., which fault has actually been activated. The available historical seismicity record, the modelling of previous damaging events, as well as the already mapped seismotectonic structures (e.g., active faults, etc.) may, under certain conditions, be useful in this regard. However, for the broader Samos area, the uncertainties in the location of historical earthquakes and the existence of three sub-parallel major fault zones that could potentially generate a $\mathbf{M} 7.0$ event, located offshore North Samos (Kaystrios or North Samos Fault), on Samos island (Pythagoreion fault) and at the southern part of the island (Cape Tsopelas fault), did not allow the unequivocal correlation of the earthquake to an existing fault zone. However, since results from preliminary macroseismic damage modelling suggested that the Pythagoreion and Cape Tsopelas faults had ruptured during the 1904 and 1955 similar mainshocks, the Kaystrios fault was the most probable "mature" candidate for the mainshock generation.

Although the seismic network geometry provided an adequate capability for the detection and location of $24 \mathrm{~h}$ aftershocks, that have been recorded in stations at distances of several hundreds of kilometers down to magnitudes below 3, it was not possible to draw certain conclusion on the dip direction of the fault, even though an assumption for 
a north-dipping zone could be performed (Fig. 4). However, this available seismicity information clearly associated the mainshock with the E-W trending normal Kaystrios fault, suggesting that the indications of north-dipping (similar to the proposed fault geometry, see Caputo et al. 2012; Sboras 2012) was reliable.

The first results on the co-seismic displacement field were given by the DInSAR technique. Indeed, the systematic acquisitions strategy by Sentinel-1 mission ensured the timely availability of co-seismic interferometric pairs, while online processing services on GEP (Foumelis et al. 2019) ensured the direct generation of interferometric measurements. It is estimated that completion of DInSAR processing on GEP was successful a couple of hours after the scene was published on the platform (approx. $4 \mathrm{~h}$ from sensing; similar to other dissemination portals). Thus, preliminary DInSAR results obtained in less than $24 \mathrm{~h}$ of the event can indeed be considered as operational. It is important to note that the above represents an optimum situation and delays due to image acquisition may vary ending up in reduced response from EO (up to three days). Nevertheless, this is not related to our current capacity to access and process the data practically in real time (Le Cozannet et al. 2020).

Despite the fact that the earthquake occurred offshore, the identification of areas with variable motion sign was a first indication for the delineation of the fault in the northern part of Samos. In addition, information on fault's geometry was extracted, suggesting a north-dipping normal fault; the hanging wall was clearly located in the offshore area north of Samos and along the western coasts of Turkey. Despite the above fortunate circumstance of identifying different motion patterns by DInSAR, it is true that strong motion observation (not considered in the present study), also contributed to the understanding of the fault geometry (Kalogeras et al. 2020).

Combining seismological data and spaceborne observations, a preliminary interpretation of the earthquake activity on Samos was prepared and communicated via social media as well as to authorities in less than $24 \mathrm{~h}$ of the event (ESA Sentinel Online 2020). Based on the information available at the time, it seemed that the rupture started from the hypocenter (relocated depth $\sim 13 \mathrm{~km}$ ), possibly expanded bilaterally in both directions (East and West), rupturing an area with a length of $\sim 55 \mathrm{~km}$ and a width of $\sim 15 \mathrm{~km}$. The large fault displacements possibly occurred along the western fault segment, where the fault may have reached the surface, possibly shifting the sea bottom (though this can happen only by the associated static displacement) and triggering the observed tsunami.

On the contrary, as shown from DInSAR data, the eastern propagation of the rupture does not seem to have reached the land surface. This is critical as such information could assist several groups during their fieldwork and help assessment of damages as successfully done for other geohazard events (Cornou et al. 2020). In fact, the above finding was confirmed after the relocation of post-seismic events, which showed the absence of very shallow aftershocks.

The aftershock relocation applied allowed to better resolve the main sequence features, exploiting a large number of seismic phases that the adequate station coverage provided for aftershocks as small as $\mathbf{M} \sim 2.5$. The results revealed that the aftershocks were distributed among many distinct spatial clusters that are more pronounced and evident than in the preliminary (bulletin) locations.

Additional information on the co-seismic movements followed from the GNSS, confirming the location of the rupture zone at the North of Samos. On the contrary, the downlift at the northern part of the island was not detected due to the absence of stations in the specific area. Of importance is the first quantitative estimation of the co-seismic dilatation along the N-S direction from the GNSS data, which cannot be deduced only by the use of DInSAR. Given the range of motion in the N-S direction, which is of the order of a few tens of centimeters, and the medium resolution of the Sentinel-1 data, unfortunately, offset tracking techniques cannot be successfully applied as in the case of other earthquakes (Bacques et al. 2020). The limitation is partly due to the difficulty in the timely acquisition of very high-resolution EO imagery. In the same context, access to real-time GNSS data is also not always guaranteed since several monitoring stations are part of commercially established and operated networks, a fact that often hamper the use of GNSS data even in the case of significant geohazards.

GNSS motion vectors indicate a relatively wide area affected by the earthquake (Fig. 10) ranging from Izmir to Leros Is., in the North and South, respectively, and from Ikaria Is. in the West to the coasts of Turkey, East of Samos Island. On the other hand, improved spatial sampling by DInSAR, even with the restriction of a single LoS observable (not 3D motion as GNSS), should be interpreted with care due to the higher influence of error sources at lower magnitude displacements.

Independent observation from DInSAR came 4-5 days from the event, allowing the verification of the observed ground displacement patterns (indirect assessment of atmospheric errors) and the decomposition of motion into E-W and Up-Down motion components and finally the recognition of post-seismic deformation. The DInSAR motion decomposition and specifically the presence of motion even at the northeasternmost part of Samos, consistent with hanging wall kinematics, in combination with the relocated aftershocks, imply either the propagation of motion towards East and/or the activation of neighboring structures at the eastern part of the island. This is also in agreement with the more diffused distribution of aftershocks to the East of the epicenter, not permitting the clear identification of the main north-dipping activated zone (Fig. $4 \mathrm{~b}$ ). In fact, relocation 
results, for aftershocks as small as $\mathbf{M} \sim 2.5$, reveal that the aftershocks are distributed between many distinct spatial clusters that are more pronounced than in the preliminary locations. The DInSAR observed post-seismic motion was also verified by a near-field GNSS station, underlining the consistency of space-borne geodetic techniques. This postseismic motion was limited over the previously uplifted zone with reduced magnitude $(3-4 \mathrm{~cm})$, whereas no, at least detectable, signal was observed in the previously downlifted coastal region.

The consistency of geodetic measurements requires proper adjustment between the techniques, mainly the definition of the local reference point used during DInSAR processing. Thus, it is important to select a priori an area not affected by seismic motion. Although this can somehow be iteratively decided, having in situ observations validating our choice is still of interest. An example where no local reference could be considered as a result of wide displacement field has been presented elsewhere (Lemoine et al. 2020). In addition to restrictions of reaching the affected area in a relatively short time, including transportation issues and other societal-health constraints (e.g., in our case the COVID-19 pandemic lockdown), the access to field survey data within 5 days of the event collocated well with the availability of additional postseismic SAR acquisitions. Still in remote areas or when such expert-base observations cannot be easily arranged, the possibility to integrate strong-motion recordings and social media data for a rapid estimation of macroseismic intensities could serve as an alternative (Fayjaloun et al. 2020).

Improvements of each geodetic estimate (GNSS and DInSAR) due to availability of more precise auxiliary metadata (e.g., precise satellite orbits) are not considered critical for the early response phase, especially when induced ground motion much exceeds the accuracy of the techniques. This is easily reflected in the modelling attempts, undertaken at different times after the earthquake and by different inputs datasets. Although the preliminary $24-\mathrm{h}$ solution was more or less reasonable, improvements in the definition of the fault geometry, in terms of misfits (Fig. 12), were more sensitive to the plethora of input datasets (multiple independent DInSAR observations and number of GNSS station involved) and less to the accuracy of the measurements themselves.

It was realized that initial hypothesis on the earthquake mechanism did not change drastically, meaning that $24 \mathrm{~h}$, preliminary results was enough to properly address rapid response needs. Nevertheless, improved data flow over the next 4-5 days amended the initial modelling results providing enhanced constraints on the rupture geometry, valuable information for following numerical simulations and damage assessment activities. It is of course expected that this information shall be further improved in time by feeding more precise inputs to models of higher complexity; yet, this is more a topic of scientific interest and less of rapid response.

\section{Conclusions}

We have combined existing knowledge, including geodatabases concerning historical seismicity and rupture zones with seismological and geodetic measurements as well as modelling and in situ observations to rapidly respond to the M7.0 Samos event. We demonstrated that in the frame of the gradual provision of information from the individual scientific disciplines and taking into account their respective limitations, we were able through a multidisciplinary approach to address more efficiently rapid response requirements. This allowed more effective preliminary interpretation of the earthquake activity, even within first $24 \mathrm{~h}$ of the event. Within a period of less than a week, several constraints regarding either data access or inherited limitations of the techniques were partially compensated for, leading to the delivery of more robust results and interpretation.

Concluding, it is worth mentioning that information and modelling of historical seismicity as well as geodatabases of mapped active fault zones can be important during early response phase. However, they often involve significant uncertainties and should be carefully assessed on a case by case basis, especially when different seismogenic fault zones are being activated. On the contrary, seismological data have long proved their contribution within a short time from the occurrence of a seismic event. Still full automation of improved data analysis has not been yet achieved and a minimal human intervention is often necessary. Similarly, GNSS has proven capabilities and reliability, with the problem being identified either in the number of pre-installed monitoring stations or in the easy and free access to the data of existing networks (especially those maintained by private entities). As far as EO is concerned, it has in turn demonstrated its capabilities and the maturity of its products. In recent years, however, due to the availability of both open access data and the development of dedicated exploitation platforms, the DInSAR technique have met the needs of an operational tool. New developments in the field of proprietary satellite missions promise a considerable reduction in response time, however, the usability of those data in terms of access and cost for geohazards remains an open issue. Compared to previously mentioned techniques and during early response phase the modelling requirements are relatively low as simple models are usually applied to address the needs of an approximate determination of the fault geometry. The final result is often mostly influenced by the number and relative accuracy of model inputs. Finally, the contribution of in situ information cannot be ruled out, though, in most cases such observations are absent and 
attempts to incorporate new approaches such as social media data or crowdsourcing into supplementary rapid response process should be evaluated.

The study highlights the readiness level of the various domains that has been significantly improved over the past years, including rapid seismological solutions, systematic availability of open access EO data and on-demand online processing through dedicated platforms (both GNSS and EO data). This wealth of data is combined by routinely applied inversion modelling and timely in situ observations, is leading to operational response levels. Still and despite our successful efforts, remaining limitations concerns the timely access to critical data. Independently of the nature of those data, an effort should be made within already existing initiatives to ensure open and free access to the science community in relatively short time following geohazard events. Such platform-based approach, for both data dissemination and processing, would guarantee improvement of our disaster response in the future.

Supplementary Information The online version contains supplementary material available at https://doi.org/10.1007/s11600-021-00578-6.

Acknowledgements Authors would like to acknowledge ESA and GEP for accessing platform resources and services, RSS for provision of a virtual machine for EO data processing and Elias P. Karathanasis and family, for their support in fieldwork and their hospitality during the COVID-19 lockdown. Metrica S.A. is kindly acknowledged for provision of GNSS data for CHIO, IKAR, MYKN and SAMO stations. Geophysics Department Contribution 947.

\section{Declarations}

Conflict of interest The authors declare that they have no conflict of interest.

\section{References}

Akyol N, Zhu L, Mitchell BJ, Sözbilir H, Kekovalı K (2006) Crustal structure and local seismicity in western Anatolia. Geophys J Int 166(3):1259-1269. https://doi.org/10.1111/j.1365-246X.2006. 03053.x

Alkan RM, Erol S, Ozulu IM, Ilci V (2020) Accuracy comparison of post-processed PPP and real-time absolute positioning techniques. Geomat Nat Haz Risk 11(1):178-190. https://doi.org/10.1080/ 19475705.2020.1714752

Aschbacher J, Milagro-Perez MP (2012) The European Earth monitoring (GMES) programme: status and perspectives. Remote Sens Environ 120:3-8

Aslan G, Foumelis M, Raucoules D, De Michele M, Bernardie S, Cakir $\mathrm{Z}$ (2020) Landslide inventory mapping and monitoring using persistent scatterer interferometry (PSI) technique in the French alps. Remote Sens 12(8):1305. https://doi.org/10.3390/rs12081305

Bacques G, de Michele M, Foumelis M, Raucoules D, Lemoine A, Briole P (2020) Displacement field of the Mw7.5 Sulawesi earthquake from Copernicus Sentinel 1-2 offset tracking and modeling: Strike slip motion on two sub-parallel faults branches could explain the tsunami genesis. Nat Sci Rep 10:9103. https:// doi.org/10.1038/s41598-020-66032-7

Bally P (ed) (2013) Satellite earth observation for geohazard risk management: the Santorini conference - Santorini, Greece, 21-23 May 2012 ESA Publication STM-282. https://doi.org/ 10.5270/esa-geo-hzrd-2012, http://esamultimedia.esa.int/docs/ EarthObservation/Geohazards/esa-geo-hzrd-2012.pdf

Boore DM (2009) Comparing Stochastic point-source and finitesource ground-motion simulations: SMSIM and EXSIM. Bull Seism Soc Am 99(6):3202-3216

Boore DM, Stewart JP, Seyhan E, Atkinson GM (2014) NGA-West2 equations for predicting PGA, PGV, and 5\% damped PSA for shallow crustal earthquakes. Earthq Spectra 30(3):1057-1085

Caputo R, Chatzipetros A, Pavlides S, Sboras S (2012) The Greek database of seismogenic sources (GreDaSS): state-of-the-art for northern Greece. Ann Geophys 55(5):859-894

Casu F et al (2014) SBAS-DInSAR parallel processing for deformation time-series computation. IEEE J Sel Top Appl Earth Observ Remote Sens 7(8):3285-3296. https://doi.org/10.1109/ JSTARS.2014.2322671

Chatzipetros A, Kiratzi A, Sboras S, Zouros N, Pavlides S (2013) Active faulting in the north eastern Aegean Sea Islands. Tectonophysics 597-598:106-122

Chatzipetros A, Pavlidis S, Zouros N (2020) Preliminary report for the Samos earthquake (30/10/2020), Aristotle University of Thessaloniki (AUTh), Department of Gelogy, p 5 (in Greek)

Cigna F, Tapete D (2020) Present-day land subsidence rates, surface faulting hazard and risk in Mexico City with 2014-2020 Sentinel-1 IW InSAR. Remote Sens Environ 253:112161. https:// doi.org/10.1016/j.rse.2020.112161

Cornou C, Aubert C, Audin L, Ampuero J-P, Baize S, Brenguier F, Causse M, Chlieh M, Combey A, Delouis B, Deschamps A, Ferry M, Foumelis M et al (2020) Rapid response to the Mw 4.9 earthquake of November 11, 2019 in Le Teil, Lower Rhône Valley, France. Comptes Rendus Géosciences. https://doi.org/ 10.31219/osf.io/3afs5

Daout S, Steinberg A, Isken MP, Heimann S, Sudhaus H (2020) Illuminating the spatio-temporal evolution of the 2008-2009 Qaidam earthquake sequence with the joint use of InSAR time series and teleseismic data. Remote Sens 12:2850. https://doi. org/10.3390/rs12172850

Delgado Blasco JM, Foumelis M, Stewart C, Hooper A (2019) Measuring Urban Subsidence of Broader Rome (Italy) by Sentinel-1 SNAP-StaMPS persistent scatterer interferometry. Remote Sens 11(2):129. https://doi.org/10.3390/rs11020129

ESA Sentinel Online (2020) Copernicus Sentinel-1 supports timely interpretation of Southern Europe's earthquake, Sentinel Online Article, European Space Agency, 12 November 2020. https:// sentinel.esa.int/web/sentinel/news/success-stories/

Fayjaloun R, Gehl P, Auclair S, Boulahya F, Guérin-Marthe S, Roullé A (2020) Integrating strong-motion recordings and twitter data for a rapid shakemap of macroseismic intensity. Int J Disaster Risk Reduct 101927:2212-4209. https://doi.org/10. 1016/j.ijdrr.2020.101927

Foumelis M, Papadopoulou T, Bally P, Pacini F, Provost P, Patruno J (2019) Monitoring geohazards using on-demand and systematic services on ESA's geohazards exploitation platform IEEE international geoscience and remote sensing symposium (IGARSS 2019) Yokohama Japan 28 July-2 August. https://doi.org/10. 1109/IGARSS.2019.8898304

Ganas, A, Tsironi, V, Kollia, E, Delagas, M, Tsimi, C, Oikonomou, A (2018) Recent upgrades of the NOA database of active faults in Greece (NOAFAULTs). In: 19th general assembly of WEGENER, September 2018, Grenoble, p 219400. https://doi. org/10.5281/zenodo.3483136 
Ganas A, Elias P, Briole P, Tsironi V, Valkaniotis S, Escartin J, Karasante I, Efstathiou E (2020) Fault responsible for Samos earthquake identified. Temblor. https://doi.org/10.32858/temblor.134

Geohazards Exploitation Platform (GEP) (2020) Access to Publicly available data, products and more. https://geohazards-tep.eu/geobr owser/?id=globalapp\#!\&context=Community\%2FSharedJobs. Accessed 31 Dec 2020

Gisinger C, Suchandt S, Breit H, Balss U, Lachaise M, Fritz T, Eineder M, Miranda N (2019) Towards operational SAR imaging geodesy: an extended time annotation dataset for sentinel-1 image products. In: Presented at the "Very High-resolution Radar \& Optical Data Assessment (VH-RODA)" workshop, 18-22 November 2019, Frascati, Italy

Grinter T, Janssen V (2012) Post-processed precise point positioning: a viable alternative? In: Proceedings of the 17th Association of Public Authority Surveyors Conference (APAS2012), Wollongong, New South Wales, Australia, Mar 19-21, pp 83-92

Hanks TC, Kanamori H (1979) A moment magnitude scale. J. Geophys. Res. Solid Earth 84(B5):2348-2350. https://doi.org/10. 1029/JB084iB05p02348

Heimann S, Isken M, Kühn D, Sudhaus H, Steinberg A, VasyuraBathke H, Daout S, Cesca S, Dahm T (2018) Grond: a probabilistic earthquake source inversion framework. V. 1.0. GFZ Data Serv. https://doi.org/10.5880/GFZ.2.1.2018.003

Isken M, Sudhaus H, Heimann S, Steinberg A, Daout S, VasyuraBathke H (2017) Kite: software for rapid earthquake source optimisation from InSAR surface displacement. GFZ Data Serv. https://doi.org/10.5880/GFZ.2.1.2017.002

Jónsson S, Zebker H, Segall P, Amelung F (2002) Fault slip distribution of the $1999 \mathrm{Mw} 71$ Hector Mine, California, earthquake, estimated from satellite radar and GPS measurements. Bull. Seism. Soc. Am. 92(4):1377-1389

Kalogeras I, Melis NS, Kalligeris N (2020) The earthquake of October 30th, 2020 at Samos, Eastern Aegean Sea, Greece. Preliminary Report, National Observatory of Athens, Institute of Geodynamics. https://accelnet.gein.noa.gr/2020/11/09/the-earthquake-ofoctober-30th-2020-at-samos-eastern-aegean-sea-greece-preli minary-report

Karakostas VG, Papadimitriou EE, Karakaisis GF, Papazachos CB, Scordilis EM, Vargemezis G, Aidona E (2003) The 2001 Skyros, northern Aegean, Greece, Earthquake sequence: Off fault aftershocks, tectonic implications, and seismicity triggering. Geophys Res Lett 30(1):1012. https://doi.org/10.1029/2002GL015814

Karakostas V, Karagianni E, Paradisopoulou P (2012) Space-time analysis, faulting and triggering of the 2010 earthquake doublet in western Corinth Gulf. Nat Haz 63:1181-1202

Karakostas V, Kostoglou A, Chorozoglou D, Papadimitriou E (2020) Relocation of the 2018 Zakynthos, Greece, aftershock sequence: spatiotemporal analysis deciphering mechanism diversity and aftershock statistics. Acta Geophys 68:1263-1294

Karakostas VG, Tan O, Kostoglou A, Papadimitriou EE, Bonatis P (2021). Seismotectonic implications of the 2020 Samos, Greece, Mw7.0 mainshock based on high - resolution aftershock relocation and source slip model. Acta Geophys (this issue)

Kiratzi A, Özacar AA, Papazachos C, Pinar A (eds) (2020) Regional tectonics and seismic source of the M7.0 Samos earthquake, special volume on the Samos M7.0 2020 earthquake, Chapter 1, 46pp

Kkallas C, Papazachos CB, Margaris BN, Boore D, Ventouzi C, Skarlatoudis A (2018) Stochastic strong ground motion simulation of the Southern Aegean Sea Benioff zone intermediate-depth earthquakesstochastic strong ground motion simulation of the Southern Aegean sea intermediate-depth earthquakes. Bull Seismol Soc Am 108(2):946-965

Klein FW (2000) User's guide to HYPOINVERSE-2000, a Fortran program to solve earthquake locations and magnitudes. U. S. Geol. Surv. Open File Report, 02-171, Version 1.0
Le Cozannet G, Kervyn M, Russo S, Ifejika Speranza C, Ferrier P, Foumelis M, Lopez T, Modaressi H (2020) Space-based Earth observations for disaster risk management. Surv Geophys. https:// doi.org/10.1007/s10712-020-09586-5

Lekkas E et al (2020) The October 30, 2020, Mw 6.9 Samos (Greece) earthquake. Newsletter of Environmental, Disaster, and Crises Management Strategies, Issue No. 21, November 2020. https:// edcm.edu.gr/en/newsletter/newsletter-21-the-october-30-2020mw-69samosgreece-earthquake

Lemoine A, Bertil D, Roullé A, Briole P, Foumelis M, Raucoules D, de Michele M (2020) The volcano tectonic crisis of 2018 east of Mayotte, Comoros islands. Geophys J Int. https://doi.org/10. 1093/gji/ggaa273

Leptokaropoulos KM, Karakostas VG, Papadimitriou EE, Adamaki AK, Tan O, İnan S (2013) A homogeneous earthquake catalogue compilation for western turkey and magnitude of completeness determination. Bull Seismol Soc Am 103(5):2739-2751

Manunta M et al (2019) The parallel SBAS approach for Sentinel-1 interferometric wide swath deformation time-series generation: algorithm description and products quality assessment. IEEE Trans Geosci Remote Sens 57(9):6259-6281. https://doi.org/10. 1109/TGRS.2019.2904912

Marchetti PG, Rivolta G, D'Elia S, Farres J, Mason G, Gobron N (2012) A model for the scientific exploitation of earth observation missions: the ESA research and service support. IEEE Geosci Remote Sens 162:10-18

Michetti AM, Esposito E, Guerrieri L, Porfido S, Serva L, Tatevossian R, Vittori E, Audemard F, Azuma T, Clague J, Comerci V, Gürpinar A, McCaplin J, Mohammadioun B, Mörner NA, Ota Y, Roghozin E (2015) Environmental SeismicIntensity scale_ESI 2007 (English). In: Guerrieri L (ed) Earthquake environmental effects for seismic hazard assessment: the ESI intensity scale and the EEE catalogue, Mem. Descr. Carta Geol. D'It. XCVII (2015), pp 11-20

Morishita Y, Lazecky M, Wright TJ, Weiss JR, Elliott JR (2020) LiCSBAS: an open-source InSAR time series analysis package integrated with the LiCSAR automated Sentinel-1 InSAR processor. Remote Sens 12:424

Motazedian D, Atkinson GM (2005) Stochastic finite-fault modeling based on a dynamic corner frequency. Bull Seismol Soc Am 95(3):995-1010. https://doi.org/10.1785/0120030207

Mountrakis D, Kilias A, Vavliakis E, Psilovikos A, Thomaidou E (2003) Neotectonic map of Samos Island (Aegean Sea, Greece): implication of geographical information systems in the geological mapping. In: Proceedings of the 4th European Congress on regional geoscientific cartography and information systems, Bologna, Italy, 11-13

Mountrakis D, Kilias A, Vavliakis E, Psilovikos A, Karakaisis G, Papazachos C, Thomaidou E, Seitanidis G (2006) Neotectonic map of Greece, Samos sheet (1:75,000 scale), Earthquake Planning and Protection Organization of Greece

Natural Resources Canada (2019) Precise point positioning. https:// webapp.geod.nrcan.gc.ca/geod/tools-outils/ppp.php. Accessed 2 Aug 2019

Nocquet JM (2012) Present-day kinematics of the Mediterranean: a comprehensive overview of GPS results. Tectonophysics 579:220-242

Okada Y (1985) Surface deformation due to shear and tensile faults in a half-space. Bull Seism Soc Am 75(4):1135-1154

Okuwaki R (2020) rokuwaki/2020Greece: preliminary tele-seismic finite-fault models of the 2020 Greece earthquake. https://github. com/rokuwaki/2020Greece

Panagiotopoulos DG, Papazachos BC (1985) Travel times of Pn-waves in the Aegean and surrounding area. Geophys J R Astron Soc 80:165-176

Papadimitriou P, Kapetanidis V, Karakonstantis A, Spingos I, Kassaras I, Sakkas V, Kouskouna V, Karatzetzou A, Pavlou K, Kaviris G, 
Voulgaris N (2020) First results on the Mw $=6.9$ Samos earthquake of October 2020. Bull Geol Soc Greece 56(1):251-279. https://doi.org/10.12681/bgsg.25359

Papadimitriou P, Kapetanidis V, Karakostantis A, Spingos I, Pavlou K, Kaviris G, Kasaras I, Sakkas V, Voulgaris N (2021) The 25 October 2018 Zakynthos (Greece) earthquake: seismic activity at the transition between a transform fault and a subduction zone. Geophys J Int 225:15-36

Papageorgiou E, Foumelis M, Trasatti E, Ventura G, Raucoules D, Mouratidis A (2019) Multi-sensor SAR geodetic imaging and modelling of Santorini volcano post-unrest response. Remote Sens 11:259. https://doi.org/10.3390/rs11030259

Papazachos CB (2019) Deep structure and active tectonics of the South Aegean volcanic arc. Elements 15(3):153-158

Papazachos CB, Kiratzi AA (1996) A detailed study of the active crustal deformation in the Aegean and surrounding area. Tectonophysics 253:129-153

Papazachos BC, Papazachou C (2003) The earthquakes of Greece. Ziti publications, Thessaloniki, Greece, 286 pp. (in Greek)

Papazachos BC, Comninakis PE, Karakaisis GF, Karakostas BG, Papaioannou CA, Papazachos CB, Scordilis EM (2000) A catalogue of earthquakes in Greece and surrounding area for the period 550BC1999. Publ. Geoph. Lab., Univ. of Thessaloniki, 1, p 333

Papazachos G, Papazachos C, Skarlatoudis A, Kkallas H, Lekkas E (2016) Modelling macroseismic observations for historical earthquakes: the cases of the $M=7.0,1954$ Sofades and $M=6.8,1957$ Velestino events (central Greece). J Seismol 20(1):151-165

Peter H, Jäggi A, Fernández J, Escobar D, Ayuga F, Arnold D, Wermuth M, Hackel S, Otten M, Simons W, Visser P, Hugentobler U, Féménias P (2017) Sentinel-1A: first precise orbit determination results. Adv Space Res. https://doi.org/10.1016/j.asr.2017.05.034

Sakellariou D, Tsampouraki-Kraounaki K (2019) Plio-quaternary extension and strike-slip tectonics in the Aegean. In: João C (ed) Transform plate boundaries and fracture zones. Springer, Duarte, pp 339-374

Sboras S (2012) The Greek database of seismogenic sources: seismotectonic implications for North Greece. PhD Thesis, University of Ferrara, Ferrara, 252 pp
Segou M (2020) What do we know 48 hours after the Samos earthquake? Temblor. https://doi.org/10.32858/temblor.132

Serva L, Blumetti AM, Esposito E, Guerrieri L, Michetti AM, Okumura K, Porfido S, Reicherter K, Silva PG, Vittori E (2015) Earthquake environmental effects and seismic hazard assessment: the lessons of some recent large earthquakes. Mem Descr Carta Geol D'It XCVII 2015:5-8

Tan O, Papadimitriou E, Pabuccu Z, Karakostas V, Yoruk A, Leptokaropoulos K (2014) A detailed analysis of microseismicity in Samos and Kusadasi (eastern Aegean Sea) areas (2014). Acta Geophys 62:1283-1309. https://doi.org/10.2478/s11600-013-0194-1

Theodoropoulos D (1979) Samos Island, geological map 1:50,000 with explanations. Institute for Geological and Mining Research, Athens

Vassilakis E, Foumelis M, Erkeki A, Kotsi E, Parcharidis Is, Lekkas E (2020) Post-event surface deformation of Amyntaio slide (Greece) by complementary analysis of Remotely Piloted Airborne System imagery and SAR interferometry. J Appl Geom. https://doi.org/ 10.1007/s12518-020-00347-y

Wang R, Lorenzo MF, Roth F (2006) PSGRN/PSCMP: a new code for calculating co- and post-seismic deformation, geoid and gravity changes based on the viscoelastic-gravitational dislocation theory. Comput Geosci 32(4):527-541. https://doi.org/10.1016/j.cageo. 2005.08.006

Wegnüller U, Werner C, Strozzi T, Wiesmann A, Frey O, Santoro M (2016) Sentinel-1 support in the GAMMA Software. Proc Comput Sci 100:1305-1312. https://doi.org/10.1016/j.procs.2016.09.246

Weidmann M, Solounias N, Drake RE, Curtis GH (1984) Neogene stratigraphy of the Eastern basin, Samos island, Greece. Geobios 17:477-490. https://doi.org/10.1016/S0016-6995(84)80020-0

Yilmaz Y, Genç ŞC, Gürer F, Bozcu M, Yilmaz K, Karacik Z, Altunkaynak S, Elmas A (2000) When did the Western Anatolian Grabens begin to develop? Geol Soc Lond Spec Publ 173:353-384. https://doi.org/10.1144/GSL.SP.2000.173.01.17

Zumberge JF, Heflin M, Jefferson DC, Watkins M, Webb F (1997) Precise point positioning for the efficient and robust analysis of GPS data from large networks. J Geophys Res. https://doi.org/10. 1029/96JB03860

\section{Authors and Affiliations}

\section{Michael Foumelis ${ }^{1} \cdot$ Costas Papazachos $^{2}$ - Eleftheria Papadimitriou ${ }^{2} \cdot$ Vasileios Karakostas $^{2} \cdot$ Dimitrios Ampatzidis $^{1}$. Giorgos Moschopoulos ${ }^{3}$. Anastasios Kostoglou ${ }^{2} \cdot$ Maya llieva $^{4}$. Despina Minos-Minopoulos ${ }^{5}$. Antonios Mouratidis ${ }^{1} \cdot$ Charalambos Kkallas $^{2} \cdot$ Alexandros Chatzipetros $^{6}$}

\author{
Costas Papazachos \\ kpapaza@geo.auth.gr \\ Eleftheria Papadimitriou \\ ritsa@geo.auth.gr \\ Vasileios Karakostas \\ vkarak@geo.auth.gr \\ Dimitrios Ampatzidis \\ dampatzi@geo.auth.gr \\ Giorgos Moschopoulos \\ moschopoulos@gmail.com \\ Anastasios Kostoglou \\ akostog1@geo.auth.gr \\ Maya Ilieva \\ maya.ilieva@upwr.edu.pl
}

Despina Minos-Minopoulos

dminou@culture.gr

Antonios Mouratidis

amourati@auth.gr

Charalambos Kkallas

chkkalla@geo.auth.gr

Alexandros Chatzipetros

ac@geo.auth.gr

1 Department of Physical and Environmental Geography, Aristotle University of Thessaloniki (AUTh), 54124 Thessaloniki, Greece

2 Department of Geophysics, Aristotle University of Thessaloniki (AUTh), 54124 Thessaloniki, Greece 
3 Department of Cadaster, Photogrammetry and Cartography, Aristotle University of Thessaloniki (AUTh), 54124 Thessaloniki, Greece

4 Institute of Geodesy and Geoinformatics, Wroclaw University of Environmental and Life Sciences, 50-357 Wroclaw, Poland
5 Ephorate of Antiquities of Cyclades, Ministry of Culture and Sports, 10555 Athens, Greece

6 Department of Geology, Aristotle University of Thessaloniki (AUTh), 54124 Thessaloniki, Greece 